Review

\title{
Linking Economic Complexity, Diversification, and Industrial Policy with Sustainable Development: A Structured Literature Review
}

\author{
Diogo Ferraz $^{1,2, *(\mathbb{D})}$, Fernanda P. S. Falguera ${ }^{2} \mathbb{D}$, Enzo B. Mariano ${ }^{2}$ and Dominik Hartmann $^{3}$ \\ 1 Department of Economics (DEECO), Federal University of Ouro Preto (UFOP), Rua do Catete, 166, Centro, \\ Mariana 35420-000, Brazil \\ 2 Department of Production Engineering, São Paulo State University, Avenida Engenheiro Luiz Edmundo \\ Carrijo Coube, 14-01, Núcleo Residencial Presidente Geisel, Bauru 17033-360, Brazil; \\ fernanda.sartori@unesp.br (F.P.S.F.); enzo.mariano@gmail.com (E.B.M.) \\ 3 Department of Economics and International Relations, Federal University of Santa Catarina (UFSC), \\ Rua Eng. Agronômico Andrei Cristian Ferreira, s/n, Florianópolis 88040-900, Brazil; \\ dominik.hartmann@ufsc.br \\ * Correspondence: diogo.ferraz@ufop.edu.br
}

check for updates

Citation: Ferraz, D.; Falguera, F.P.S.; Mariano, E.B.; Hartmann, D. Linking Economic Complexity, Diversification, and Industrial Policy with Sustainable Development: A Structured Literature Review. Sustainability 2021, 13, 1265. https://doi.org/10.3390/su13031265

Academic Editors: Marc A. Rosen,

César A. Hidalgo,

María Semitiel-García, Philipp Aerni and Markus Schaefer

Received: 30 October 2020

Accepted: 21 January 2021

Published: 26 January 2021

Publisher's Note: MDPI stays neutral with regard to jurisdictional claims in published maps and institutional affiliations.

Copyright: (C) 2021 by the authors. Licensee MDPI, Basel, Switzerland. This article is an open access article distributed under the terms and conditions of the Creative Commons Attribution (CC BY) license (https:/ / creativecommons.org/licenses/by/ $4.0 /)$.

\begin{abstract}
Research on economic diversification and complexity has made significant advances in understanding economic development processes, but has only recently explored environmental and social sustainability considerations. In this article we evaluate the current state of this emerging literature and reveal 13 research gaps. A total of 35 different keywords and methods from structured literature reviews and network science helped to identify 374 scientific articles between 1988 and 2020 and revealed a fragmented research landscape around three larger network communities: (1) industrial policies, climate change, and green growth; (2) economic complexity and its association with inequality and environmental sustainability; and (3) economic diversification, including studies on livelihood diversification in poor areas. Economic complexity research applies new empirical methods and considers both social and environmental sustainability, but seldom scrutinizes theory and policy. Industrial policy research focuses on green growth policies but tends to omit social sustainability issues and advanced empirical methods. Research on economic diversification in poor regions provides insights on the livelihood diversification of farmers, but is disconnected from the economic complexity and industrial policy research. This review helps to summarize the main contributions and shows pathways for potential mutual learning between these communities for the sake of sustainable development.
\end{abstract}

Keywords: systematic literature review (SLR); economic complexity; human development; sustainability; rural livelihood; diversification; industrial policy

\section{Introduction}

Since the seminal work of Hidalgo et al. [1] and Hidalgo and Hausmann [2], a considerable body of literature has explored the economic complexity of countries and regions [3-5] and has shown how the network structure of production and type of economic activities condition economic growth and future diversification of economies. Only in recent years, though, have studies started to consider the association between economic complexity and environmental sustainability [6-9], as well as economic complexity and social sustainability. In this literature review, we intend to summarize how the main research fields related to economic diversification and sophistication processes address social and environmental sustainability considerations.

We apply a broad perspective on economic complexity by also including previous and ongoing research efforts on economic diversification, relatedness, and industrial policies that address questions of social and environmental sustainability. The reasons 
for this are threefold. Firstly, these research communities share motivation and common goals. While different research communities can be identified within the broader field of economic diversification and sophistication, they also have strong common grounds, such as (1) emphasizing the need of moving beyond aggregate growth towards the quality of economic development, (2) pointing to the vulnerabilities of economic systems specialized in few low-value added activities, (3) highlighting the importance of knowledge-intensive activities, and (4) analyzing whether, how, why, and when these activities can be achieved. Secondly, there is significant overlap of key words. There is a strong co-occurrence of their respective research papers in systemic keywords searches in bibliographic databases, illustrating the relatedness of their research agendas. Thirdly, these communities are complementary. It is likely that their joint strengths in analyzing different aspects of economic diversification and sophistication processes are necessary to confront the social and environmental challenges of the 21st century. Indeed, despite a strikingly low level of cross-citations, the different approaches identified in this article could build upon and complement each other for a better understanding of the association between economic diversification and sophistication, and sustainability.

The role economic diversification can play in achieving economic development [10] has been debated in both the trade literature as well as regional and local development literature $[10,11]$. Economic diversification occurs when an economy increases its set of economic activities and markets in which it is engaged. Economic diversification can help economies to grow and reduce their vulnerability to economic crisis, market fluctuations, and technological changes. Additionally, research on diversification in poor agricultural areas has defined rural diversification as the process by which rural areas explore several activities and capabilities to promote income growth and improve the standard of living.

Relatedness research has advanced studies on economic diversification by focusing not only on the number of economic activities, but also exploring the extent to which these economic activities are similar to each other in terms of the productive capabilities, markets, and institutions required for producing and selling them (in a competitive manner). Strongly promoted by researchers from the field of economic geography, relatedness research has shown that a variety of related sectors is essential for regional competitiveness, growth, employment, and resilience [12,13]. These studies highlight the importance of relatedness for economic diversification strategies since economies are seldom able to move into unrelated activities [14,15], and developing related capabilities tends to be a more feasible and promising path to boost economic diversification and economic growth [11-16]. Research on the economic complexity, and in particular research associated with the product space and economic complexity index, goes one step further by considering not only the number of economic activities (i.e., economic diversification) or the similarity between these economic activities (i.e., relatedness), but also the quality and network position of these activities. The literature on economic complexity and relatedness share the understanding that new activities depend on the available knowledge and skills to produce goods and services $[1,2,4,17]$, however economic complexity research made significant advances in measuring the quality and sophistication of economic activities. For instance, the economic complexity index is inversely related to the ubiquity of economic activities, capturing that many economies are able to produce simple agricultural goods; however, only few economies are able to produce highly knowledge-intensive activities, such as specialized machine tools or medical instruments, that tend to require a network of associated economic activities [2,4]. Due to its emphasis on empirically identifying highly connected and knowledge-based activities, economic complexity studies tend to concentrate more on intensive technological products or industrial sectors than, for example, economic diversification activities of farmers in poor rural areas. Finally, the industrial policy community shares the emphasis on more value-added activities, but tends to focus more on the (general) positive effects of industrialization for economic catch-up, highlighting market failures, scrutinizing success cases, and discussing the political and macroeconomic factors that hinder or promote economic diversification and sophistication [18-21]. 
It is noteworthy that these related research communities share the same increasing concern with sustainable development, which encompasses environmental (pollutant emissions, green products, climate change) and social (human development, inequality, among others) sustainability issues to respond to worldwide challenges. Only in recent years, though, have studies started to consider the association between economic diversification and environmental sustainability [6-9], as well as social sustainability in more detail. Fields connecting economic diversification and complexity with sustainability are still emerging, and so far iterative keywords searches suggest that social sustainability considerations are mainly related to aspects of inequality and human development, such as education, health, access to infrastructure, and better job opportunities. Moreover, there is new research exploring the effects of economic diversification and complexity on environmental pollution and identified potential green growth paths [21-23].

Previous research on environmental sustainability tended to focus on the environmental capacity to absorb and recover (with great concerns related to ecology, pollution, and emissions), but has been increasingly treated as an issue of survival of the human species on earth and systemic threats associated with climate change $[6-9,16]$. This is in line with the increasing awareness and emphasis of public opinion, research, and political efforts on sustainable development. While economic progress matters for standards of living, the effects of the current economic development models on environmental pollution, climate change, and unequal distribution of income and human agency also threaten the long-term sustainability of human society and global production systems. More emphasis on sustainability is crucial because most developing countries face substantial socio-economic problems, such as high unemployment rates, income inequality, malnourishment, and inadequate basic infrastructure and health care [24]. Moreover, developed and developing countries are being challenged to promote economic growth without damaging the environment $[9,16,22]$. For example, $\mathrm{CO}_{2}$ emissions are considered the primary culprit for damaging environmental quality [6]. Although 195 countries negotiated greenhouse gas reduction during the Paris Agreement of the United Nations Framework Convention (UNFCCC) in 2015 [25], some developed countries still deny the importance of global warming worldwide [26].

All this shows the need for more inclusive and sustainable production systems. The economic goals of productive diversification, sophistication, and growth need to be combined with more comprehensive and stringent considerations of social and environmental sustainability. Here we summarize the emerging literature on this matter. Section 2 briefly presents the theoretical background. Section 3 presents our motivation, keywords, and the structure literature review. Section 4 introduces the data and procedural methods. Section 5 presents the main results, including bibliometric measures, the analysis of the main clusters and publications through citation network, as well as the main findings of the in-depth analysis related to the research strategies and scope studied. Section 6 presents a systematic analysis of the main insights of the economic complexity, industrial policy, and rural diversification communities. Section 7 identifies and discusses the main research gaps about the theme. Finally, in Section 8, we discuss the reasons for the gaps identified in the literature and offer our concluding remarks.

\section{Initial Theoretical Mapping}

Before systematizing the literature empirically, we summarize some of the main ideas and motivations of the different strands of literature in economic diversification and sophistication (in particular industrial policy, relatedness and complexity, and economic diversification in rural communities) in connection with sustainability. While we highlighted similarities above, here we also indicate some differences in their guiding ideas and main focus.

There is a long tradition in research on industrial policies. While some authors highlight the need to promote infant industries and overcome structural constraints for industrialization and economic diversification (e.g., Alex Hamilton [27], Rosenstein-Rodan [28], 
Rodrik [29], Chang [30], Hartmann [31]), other authors highlight the need for anti-trust measures and ensuring the integrity of the market forces of competition and innovation [32-35]. In consequence, diverse industrial policy definitions have also been debated in the literature $[30,36]$. One definition and related school of thought argues that industrial policy should focus on market-oriented policy measures to correct market failures. Another school of thought argues that industrial policy is or should be responsible for macroeconomic policies that affect growth, productivity, competitiveness and favor promising industries, creating skilled workforces, developing infrastructure, and regional policy to increase economic welfare [30]. Despite their differences, both approaches tend to argue that economic progress will increase social welfare, either through an increase in efficiency or diversification, as it expands production, provides jobs, and raises income. Yet dedicated in-depth studies in peer-reviewed journals on the interaction between industrial policies and social sustainability consideration, such as inequality and sustainability, are scarce. Aspects of environmental and social sustainability have only rather recently been analyzed in greater detail [21,37].

Research on relatedness and economic complexity has made significant progress towards: (1) understanding the path dependency of economic diversification processes; (2) highlighting that not only the number, but also the type and quality of economic activities (e.g., industries, occupations, technologies) matter for economic development; and (3) providing new methods and tools to identify structural constraints and opportunities for smart, inclusive, and sustainable growth [12,13,17-19,38].

Another strand of the literature in agricultural and development economics has analyzed the importance of economic diversification for the standards of living, human development, and economic resilience of the people in rural areas of less developed regions $[39,40]$. While research on industrial policies and economic complexity tends to highlight the most innovative, value-added, and complex economic activities, this strand of the literature takes a bottom-up perspective on the possibilities of local farmers and rural populations to diversify their income source, and highlights the importance of non-rural activities, such as sustainable rural tourism, as an alternative way to promote economic growth [39,41].

Research on economic complexity, diversification and industrial policies can and should contribute to this system-relevant global task. The type of economic diversification and development plays an important role in environmental degradation and social sustainability. Many studies on the social and environmental Kuznets curve have analyzed whether income inequality, per capita $\mathrm{CO}_{2}$ emissions, and non-renewable energy consumption [42] follow an inverted-U path with respect to aggregate economic growth [43]. Other studies posit a circular economy as an alternative approach to the linear economy, which benefits businesses, society, and the environment [44,45]. It is only recently, though, that approaches have emerged depicting the quality of economic development and allowing for a more disaggregated perspective on the type of economic activities and network structure of production in a region or country. This includes research on economic complexity, rural diversification, and industrial policies $[6,7,9,22]$. Their methods and insights help to move towards more focalized and effective policy measures that take the structural challenges and opportunities of each region and country into account.

Recent studies in economic complexity research tend to emphasize its overall positive effect of productive sophistication on social sustainability, inter alia, by creating more and better jobs and demanding more inclusive institutions [31,46]. However, multiple aspects, such as the regional characteristics of inclusive growth, social mobility and intersectionality, are still underexplored. The association between economic complexity and environmental sustainability has started to be increasingly debated, pointing to a certain extent of environmental Kuznets curve behavior with deceasing pollution levels at high levels of productive sophistication, though it still leaves many questions open, for example, about the precise green growth and related policies and regulation, or whether the pollution values along with simpler activities are partially being outsourced to other countries in the process. 
Here, we chose to mainly review the literature from the perspective of economic complexity and relatedness research, because it combines considerations of economic diversification and sophistication. However, we also reveal how economic complexity and relatedness research can learn from and contributed to related fields of research such as industrial policies and studies on economic diversification in rural communities.

\section{Structured Literature Review-Initial Considerations}

Recognizing the need to increasingly incorporate social and environmental sustainability in studies related to economic diversification and sophistication, and the importance of understanding the current state of this intellectual territory, it seems to be the right time for a structured literature review to synthesize the results, interpret the findings, and point out possible directions for future research.

A literature review related to such an important and growing field leads to many analysis possibilities and challenges, such as issues in understanding what is relevant to the audience, what is a too broad or a too narrow focus. As it seems to be the first literature that explicitly sought to integrate the three streams of literature on economic diversification and complexity, and sustainability, we chose to apply a data-driven approach with an iterative identification of a broad set of keywords. In addition, considering the scientific quality required, we decided to work only with peer-reviewed articles or highly cited books within curated bibliographic databases. Moreover, we also used different structured literature review techniques that complemented each other to avoid, as far as possible, a subjective or biased approach. In this sense, we broadened our analysis to capture a relatively broad set of articles associated with economic complexity and sustainability using 35 keywords identified by iterative searches in the Scopus and Web of Science databases (listed in the Materials and Methods section). This process led to 374 unique documents with adherence to our research objective. Figure 1 is an interesting way of having a first overview of the publications and the most frequent keywords of these 374 articles.

Figure 1 is based on the density view of the co-occurrence keywords map of the VOSviewer software [47]. The density of each keyword is based on their occurrences and the proximity between the terms is based on their mutual appearance (co-occurrence). The five color rainbow scheme was used, with red representing the terms with higher occurrences, followed by orange, yellow, green, and blue (lower occurrences). It is possible to see "industrial policy", "economic complexity", and "economic diversification" with the highest densities (red color), and terms like "evaluation" (at the upper left) and "regional productivity" (at the bottom left) with lower densities. Terms with a high association strength (co-occurrences in the publications database) are pulled towards each other, while nodes with a low association strength are pushed away from each other. For instance, there is a group of terms further away from the center related to "resilience", "livelihood diversification", and "off-farm income" giving us a first indication about the existence of a separated research field related to "rural diversification", which was later also demonstrated by an in-depth analysis.

Our bibliometric analysis integrates the growth of studies by research area and presents the most cited publications, which shows quantitative evidence. The analysis of the network of citations with clusters confirmed how these themes interrelate in the literature, and the in-depth analysis of the content, in addition to corroborating qualitatively, allowed us to explore the research strategies used and the topics addressed within each theme. We found three main research poles on the topics combining the network analysis and the in-depth analysis of the articles: (1) industrial policies, climate change, and green growth, (2) economic complexity and its association with inequality and environmental sustainability, and (3) economic diversification. The key search term economic diversification identifies studies in several areas, such as a highly cited cluster of research papers analyzing diversification in rural areas (see also the citation network). Moreover, multiple separate topics are explored in small thematic clusters. However, how are these different research efforts connected? Furthermore, where do they publish, what are their most 
relevant publications, which methods do they use, and which research gaps and mutual learning possibilities can be identified? In this article, we used techniques from structured literature review research to identify gaps and possibilities for mutual learning in order to build an integrated research agenda on social and environmental sustainability, associated with economic complexity, rural diversification strategies, and industrial policies.

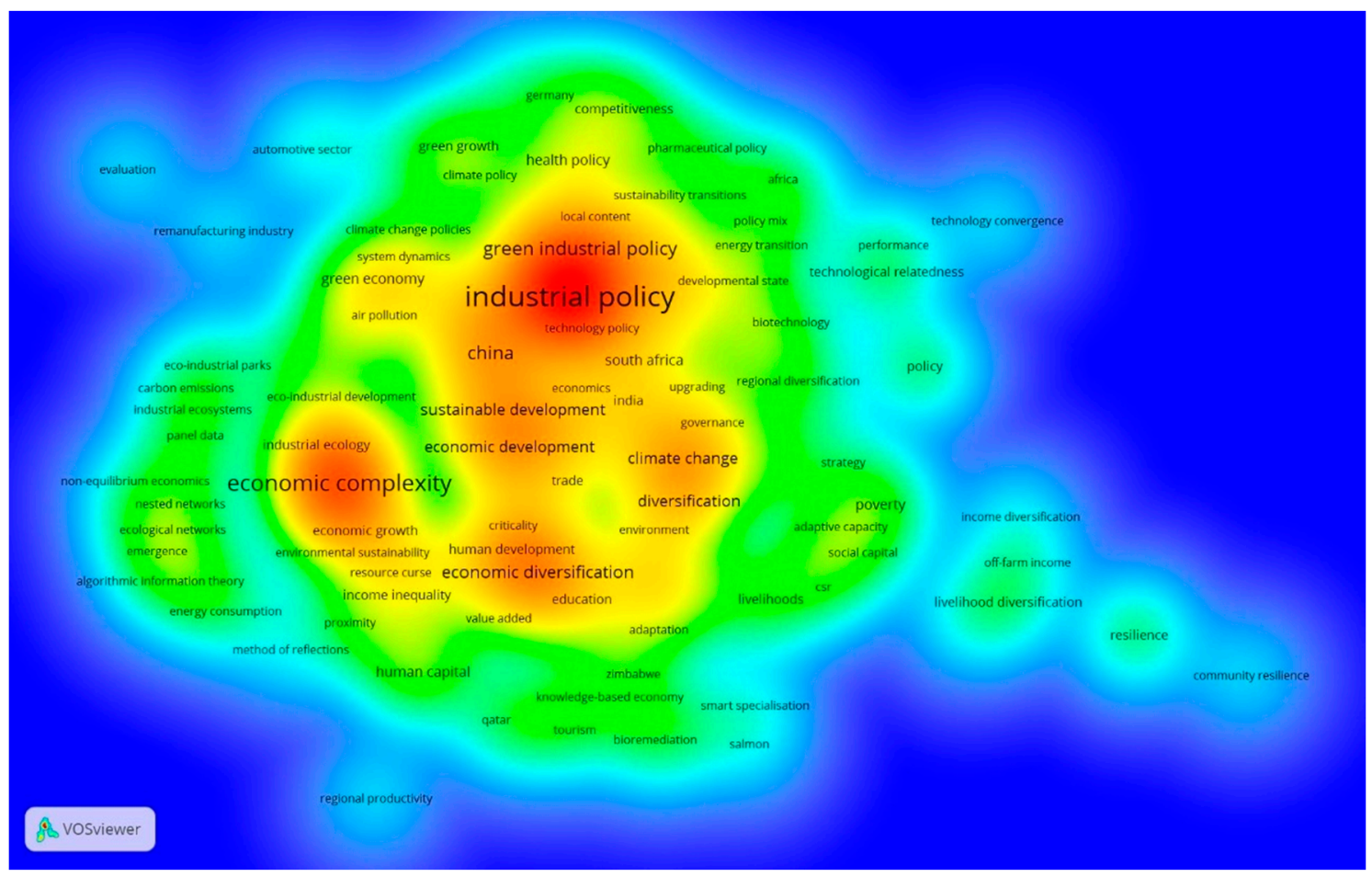

Figure 1. Density and co-occurrence of keywords in 374 research papers related to economic complexity, economic diversification, and industrial policy in association with social and environmental sustainability. This co-occurrence keywords map is made with the VOSviewer software [47]. Red indicates a more numerous occurrence of the keyword, blue a low one. The proximity between the terms is based on their mutual appearance (co-occurrence) in the publications.

Despite these growing research fields, to the best of our knowledge, an integrated structured literature review related to economic complexity, diversification, and industrial policy in association with social and environmental sustainability, is missing. Moreover, we did not find studies of literature reviews using quantitative review methods. These methods help reduce an eclectic bias that may omit some factors while overemphasize others, based on the authors own choices, and not based on the factual statistical frequency of works in the databases. Still, of course the results depend on the initial search words, such as economic complexity, diversification and sustainability. However, widening the approach from a mere keyword focus on economic complexity and sustainability to include similar related keywords that co-appear in the search process, allows us to explore relevant related ideas and reveal which fields can learn from or teach economic complexity research on social and environmental sustainability aspects.

Our study identified that a structured literature review based on this broader view could identify structural gaps and future research opportunities regarding economic diversification and complexity along with social and environmental sustainability considerations. In this respect, bibliometric analysis helped us to identify the publication dynamics, the most relevant journals, geographic focus, and research clusters. Moreover, a combination with network analysis and an in-depth qualitative analysis of the research contents of core articles helped to identify research gaps in terms of data, topics and methods, as well as reveal possibilities for mutual learning between different overlapping, or separate, areas of the literature. Thus, this survey of the literature, conducted via a structured literature 
review, presented three specific advantages. Firstly, the technique helped us to systematize the results of the articles analyzed, relating them to emerging research topics. Secondly, it allowed us to identify and analyze the most important studies in more detail. Thirdly, it helped us to identify gaps in the literature and reveal challenges for future research $[48,49]$.

\section{Materials and Methods}

The research method structure used in this study is based on other systematic literature reviews, [48-52] with some complementary steps, which can be summarized as follows:

Step 1: Refining the main keywords through a keywords co-occurrence network.

Step 2: Assessing the articles published in major databases, using a set of pre-established keywords.

Step 3: Screening the articles found by reading their titles and abstracts (filter).

Step 4: Development of the classification system that represents the object studied, applying this system to the publications filtered.

Step 5: Selection of publications for an in-depth analysis.

Step 6: Building the scientific production profile of each article selected, identifying main research strategies.

Step 7: Scope analysis of each paper selected, based on geographical area, unit of analysis and sub-area or indicators of sustainability used.

Step 8: Syntheses of the results obtained in the four analyses conducted (bibliometric, citation network, research strategies, and scope) to identify gaps and research opportunities.

The first step was defining the keywords, which were later refined through preliminary searches of the Scopus and Web of Science (WoS) databases. Next, the keywords cooccurrence map was created using the "bibliographic data" module of the VOSviewer software version 1.16.14, and its network visualization was analyzed in order to identify relevant synonyms [47].

With the keywords defined, in Step 2, searches were performed on the Scopus and WoS databases on 18 May 2020, based on the title, abstract, and keywords for articles, reviews and books or book chapters, without any time or language restriction. It is important to note that these databases were chosen as they have the most extensive global collections of articles and publishers, and have been used in several other systematic literature reviews [51-53]. The Core Collection of the WoS database was used; this collection is curated by an expert team of in-house Web of Science Editors and covers: Science Citation Index Expanded (1900-present), Social Sciences Citation Index (1900-present), Arts and Humanities Citation Index (1975-present), Conference Proceedings Citation Index- Science (1991-present), Conference Proceedings Citation Index- Social Science and Humanities (1991-present), Emerging Sources Citation Index (2015-present), Current Chemical Reactions (1985-present), Institut National de la Propriete Industrielle structure data (back to 1840) and Index Chemicus (1993-present). The content on Scopus comes from over 5000 publishers that are also reviewed and selected by an independent Content Selection and Advisory Board (CSAB). The decision to restrict to peer-reviewed journal articles and curated databases (excluding conference papers), apart from improving the quality of the sample, was considered an important scientific criteria, especially for the analysis of the leading publications in the network clusters and for the papers choice of the in-depth analysis.

Figure 2 shows the 35 keywords, which were identified by iterative searches in the Scopus and Web of Science databases. We made use of related keywords that frequently co-appeared in the identified paper. This iterative process reveals the most used keywords as well as relevant synonyms and closely related terms. Each of the keywords related to economic complexity, diversification and industrial policy (on the left), was combined with each of the keywords related to sustainable development or sustainability (on the right). The resulting combinations, more than 230, allowed us to retrieve publications that incorporate any research area with all aspects of sustainability considered. 


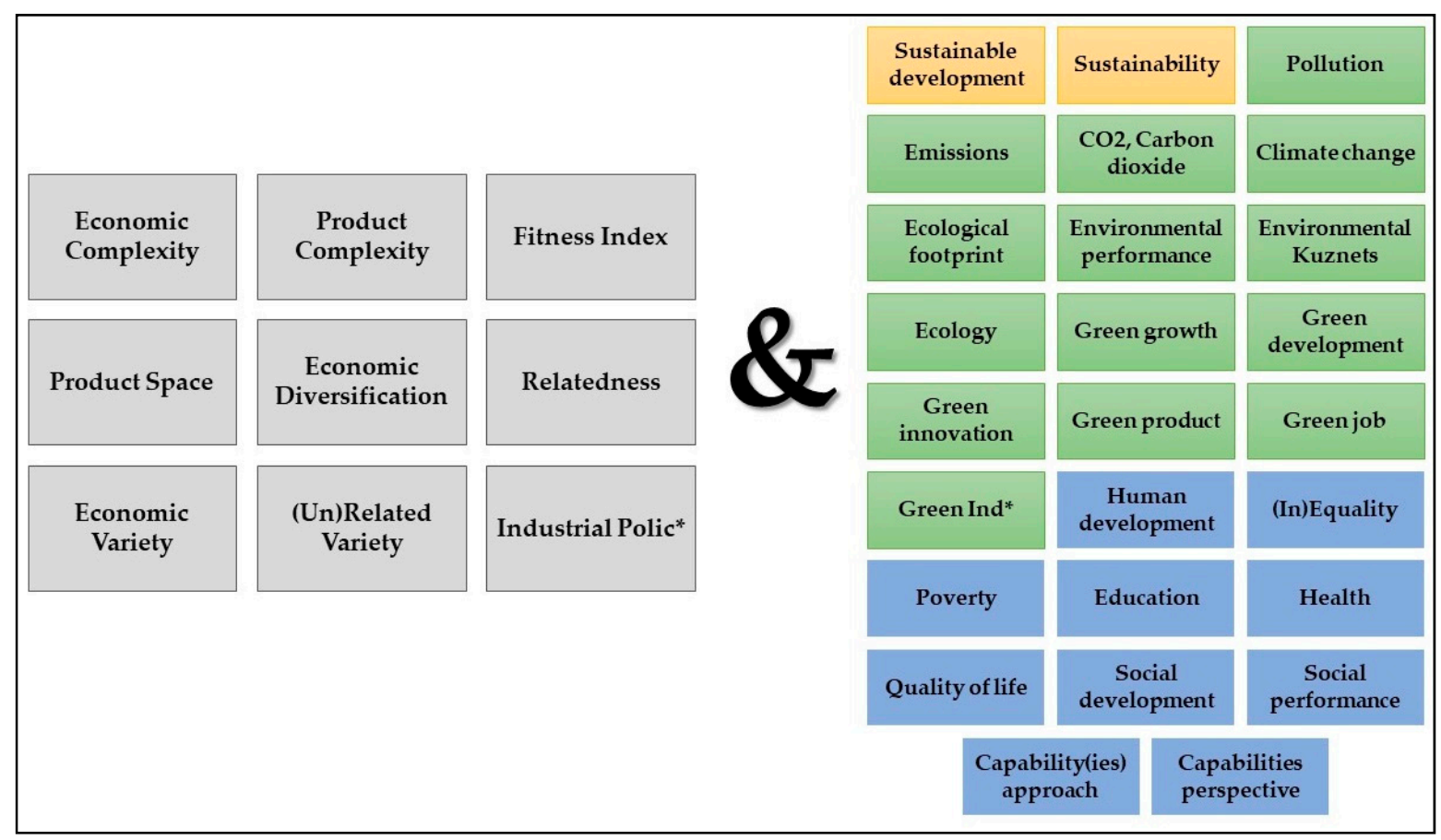

Figure 2. Keywords used in this research. Note: “’ Replaces one or more characters of a word, for example "Industrial Polic *" also includes the expressions "Industrial Policy" and "Industrial Policies".

It is worth mentioning that the final search in the bibliographic bases was carried out using the 35 terms in Figure 2 based on the keywords of the publications, but also based on their title and abstract. On the other hand, Figure 1 (at the Introduction section) presents the density map of the authors' keywords of the 374 publications found by the final search after passing in our adherence filter (screening in the title and abstract of the Step 3). This why the Figure 1 also includes contextual words (such as regional and sector-specific words, like China, South Africa, Automotive industry, etc.). These words are not part of the key search terms due to their level of specificity, but show specific contexts have already been explored in the literature that links economic diversification and sustainable development.

In Step 3, the exclusion of areas unrelated to the research, such as "medicine", "agriculture", "veterinary", among others, was carried out, and a first filter was performed based on reading the title and abstract to verify adherence to the study. Some articles were discarded because they did not consider the full research topic - for example, mathematical models studying unequal spaces.

In Step 4, the remaining publications were classified by research area (economic complexity, diversification, and industrial policy) and by sustainability dimension (social, environmental, or both) in order to generate the citation network and bibliometric analysis considering this broader context.

In Step 5, the selection of publications for the in-depth analysis was done. Then a complete reading of the papers from this selection was made, in order to identify research strategies (Step 6) and to conduct the scope analysis (Step 7).

In Step 6, structured review techniques were used, resulting in four analyses conducted in an integrated way with the previously-defined classification system: bibliometric, citation network, main research strategies, and scope analysis.

This approach allowed us to identify the gaps and research opportunities from multiple categories (Step 8). The bibliometric analysis is important in order to demonstrate the period of publications, the most relevant studies and authors, and which journals have been publishing articles in the field. The network analysis revealed the research clusters and the main references, in addition to aiding the selection of publications destined for the in-depth analysis. The main research strategies analysis helps readers to understand 
which methods are typically used to investigate research problems and which methods have not yet been applied. Furthermore, scope analyses are important tools to provide relevant information on geographical area, research unit of analysis and research sub areas, crucial to understanding whether one sub area might learn from another area.

\section{Results}

The bibliographic database search process registered 6789 publications on Scopus and 5000 on WoS. After excluding unrelated areas, 2176 documents remained. The merging process, which eliminated duplications and selected only papers with at least one link (citations or cited by) resulted in 533 documents. After passing through the filter that analyzed the requirements for adherence to the research through title and abstract reading (filter), 374 unique documents were selected. Finally, 61 publications were considered appropriate for the systematic literature review in-depth analysis. This selection process was necessary to ensure that the number of articles to be analyzed represented the most relevant studies in the main research areas.

\subsection{Bibliometric Analysis}

The first bibliometric analysis focused on the evolution of publications over time. In this respect, we observed a significant growth of publications combining aspects of economic complexity, industrial policies and diversification with aspects of social and environmental sustainability. Figure 3 shows: (a) the general growth in publications; and (b) the focus of the 374 published articles on economic complexity, diversification or industrial policy as well as on either social or environmental sustainability.

Figure 3a shows the evolution of publications over time, which confirms an exponential growth in the literature since 1988 [1,2,14] (89\% of degree of fit to an exponential curve). In this sense, Figure $3 b$ illustrates that economic complexity is a recent topic of literature compared with diversification and industrial policy. Research on rural diversification decreased in the mid-2000s, although publications increased again during the last decade. The same occurred with research on industrial policy. Figure $3 \mathrm{~b}$ also shows that studies analyzing social and environmental sustainability emerged only at the end of the first decade of the 2000s, and both have published a large number of works in the last few years.

Journals are an essential vehicle for disseminating new knowledge, especially to specific target audiences and communities. For this reason, Figure 4 presents the number of publications for the most relevant journals. Sustainability (Switzerland), Journal of Cleaner Production, Climate Policy, World Development, Energy Policy, Regional Studies, and Resources Policy make up $23 \%$ of the publications found. It is noteworthy that these journals include social and environmental sustainability approaches in their scope. Furthermore, journals like Environmental Innovation and Societal Transitions, Environmental Science and Pollution Research, Journal of Development Studies, and Technological Forecasting and Social Change published relevant papers in this field. It is also important to mention that 158 journals published just one relevant paper, and 27 journals published only two papers. This fact may indicate that the theme is still dispersed in the literature or is linked to several areas of study. 


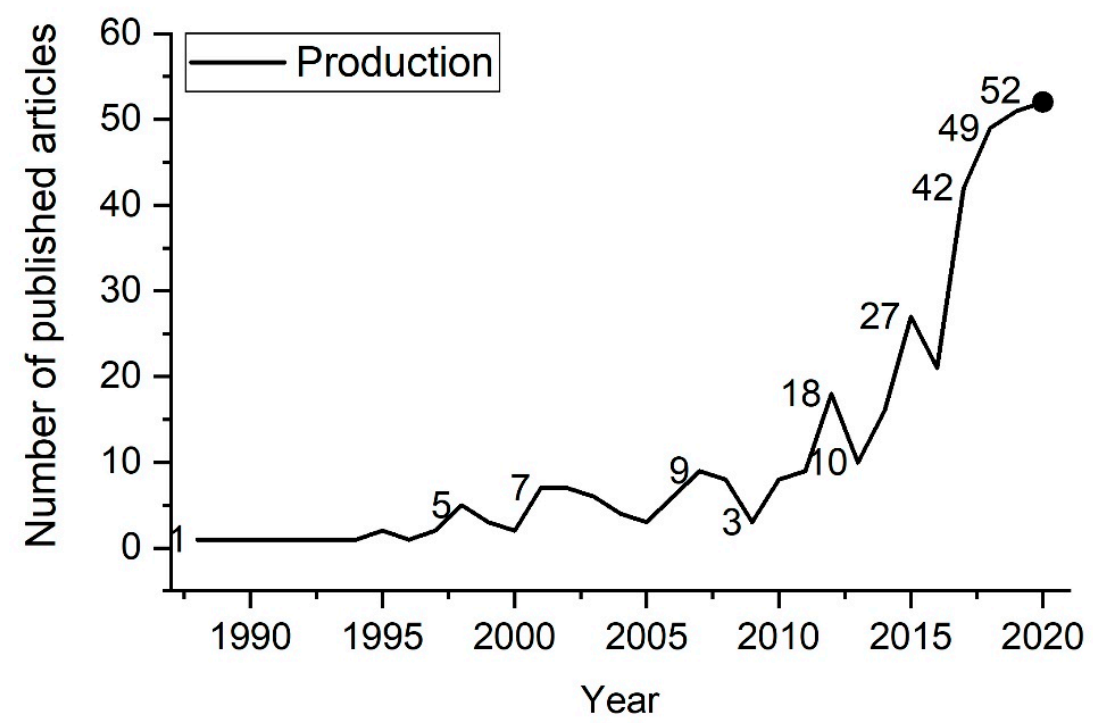

(a)

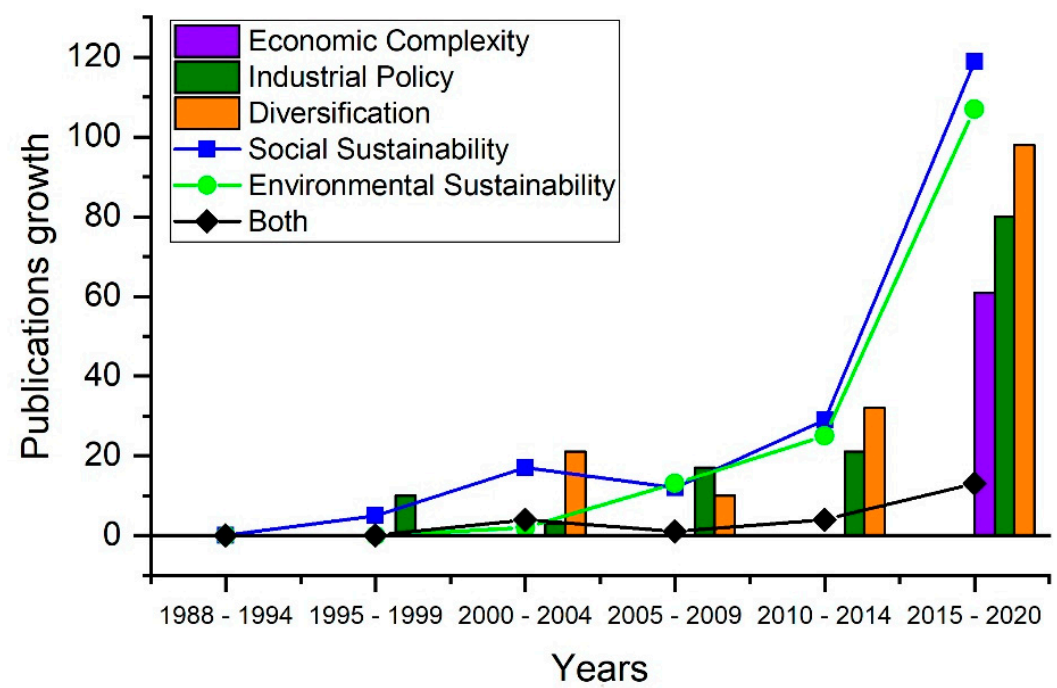

(b)

Figure 3. Bibliometrics. (a) publication growth; (b) publication growth per research area (Economic Complexity, Diversification and Industrial Policy) and sustainability dimension (social, environmental and both).

The number of citations is a useful parameter for classifying the most relevant papers. In this sense, we used both local and total citations, an important distinction when analyzing the most cited papers in the network analyzed. The local citations are citations within the network of the publications selected in our literature review (after the screening in the title and abstract process of the Step 3). Conversely, the total citation considers all of the citations that an article received. Some articles, such as Ellis (1998) and Shanahan et al. (2016) received many more citations from other research fields. Table 1 presents the most relevant publications in terms of local citations in the focus network with their overall citations. The ranking order was based on the local citations, since priority was given to the relevance under the lens of our research objective. It is noteworthy that recent papers have not had enough time to become prominent in this regard [52]. Among the articles selected, Hartmann et al. [54] was the most locally cited article in this network. This study links inequality with economic complexity worldwide, using methods from network science and econometrics. The Ellis' paper [39] received the largest number of total citations. This study presents a theoretical approach on household strategies and rural 
livelihoods in sub-Saharan Africa and Asia. Other important references are papers that analyze green industrial policy [21], complexity and economic growth [38], and a book of economic complexity and social sustainability [55].

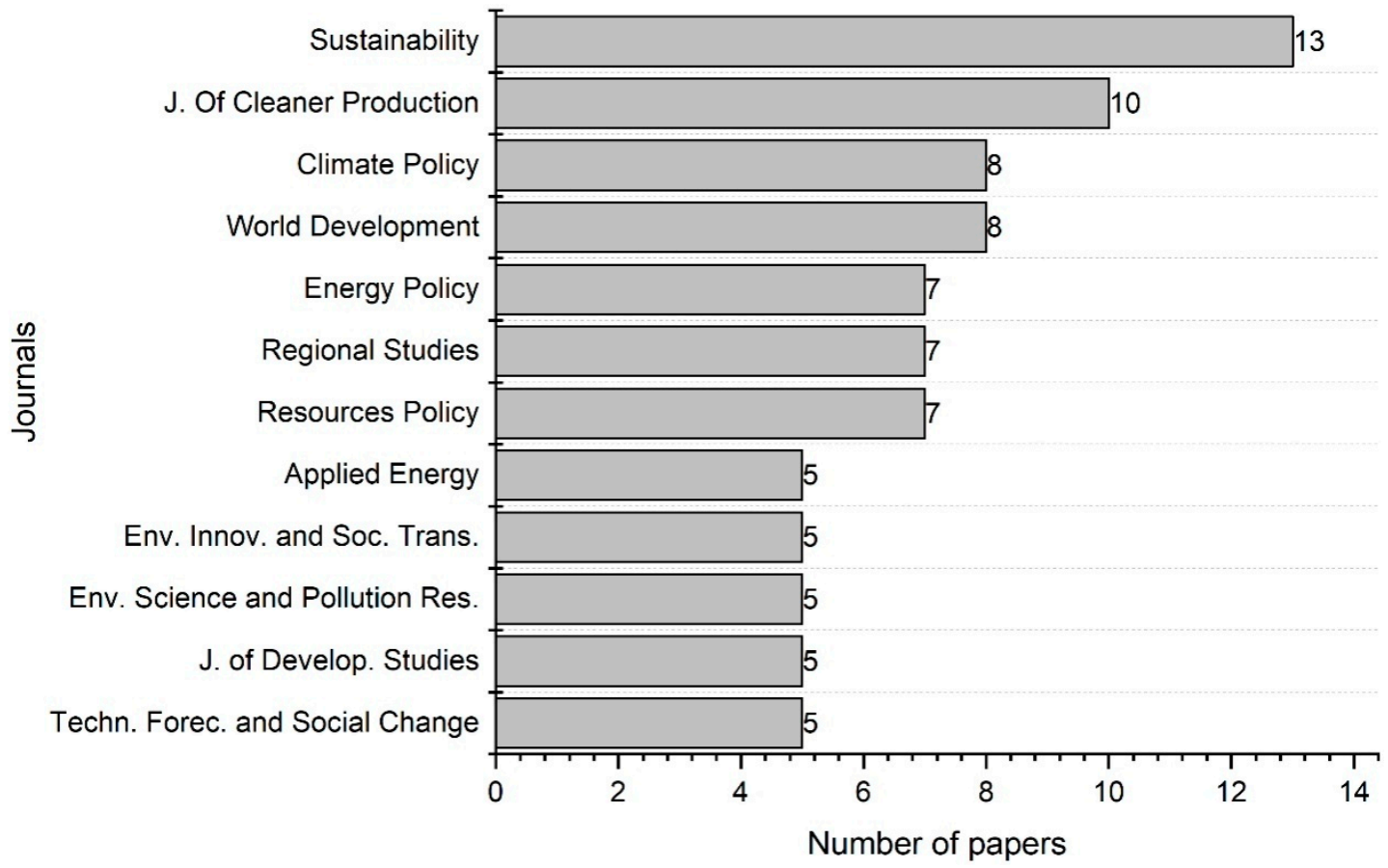

Figure 4. Most relevant journals.

Table 1. The 20 most local cited papers.

\begin{tabular}{|c|c|c|}
\hline Research & Local Citations & Total Citations \\
\hline Hartmann, D.; Guevara, M.; Jara-Figueroa, C.; Aristaran, M.; Hidalgo, C. (2017) [54] & 22 & 76 \\
\hline Ellis, F. (1998) [39] & 18 & 995 \\
\hline Rodrik, D. (2014) [21] & 15 & 100 \\
\hline Hartmann, D. (2014) [55] & 9 & 16 \\
\hline Pegels, A.; Ltkenhorst, W. (2014) [56] & 7 & 64 \\
\hline Shadlen, K.; Da, F.E. (2013) [57] & 7 & 30 \\
\hline Can, M.; Gozgor, G. (2017) [6] & 7 & 29 \\
\hline Mariani, M.; Vidmer, A.; Medo, M.; Zhang, Y. (2015) [5] & 7 & 26 \\
\hline Mathews, J. (2012) [58] & 6 & 61 \\
\hline Schmidt, T.; Huenteler, J. (2016) [59] & 6 & 40 \\
\hline Wu, M.; Salzman, J. (2013) [60] & 6 & 33 \\
\hline Lanjouw, J.; Lanjouw, P. (2001) [61] & 5 & 209 \\
\hline Mazzucato, M. (2016) [37] & 5 & 99 \\
\hline Gozgor, G. and Can, M. (2016) [9] & 5 & 27 \\
\hline Chertow, M. (2007) [62] & 4 & 562 \\
\hline Shanahan, D.; Bush, R.; Gaston, K.; Lin, B.; Dean, J.; Barber, E.; Fuller, R. (2016) [63] & 4 & 137 \\
\hline Wade, R. (2012) [64] & 4 & 84 \\
\hline Barrett, C.; Bezuneh, M.; Clay, D.; Reardon, T. (2001) [65] & 4 & 82 \\
\hline Wixe, S. (2015) [20] & 4 & 18 \\
\hline
\end{tabular}

\subsection{Network Analysis}

Figure 5 presents the citation network generated from the 374 papers chosen. The nodes are represented by the publications and the links are represented by arrows, which indicate the direction of knowledge flow (cited node points to the citing node). The size of the nodes is based on their local citations in the network, which is the absolute number of links that the publication has inside this network of identified main papers. 
Each sustainability dimension is represented by a different node shape, such as an ellipse representing social sustainability, a box environmental sustainability, and a diamond a combination of these dimensions.

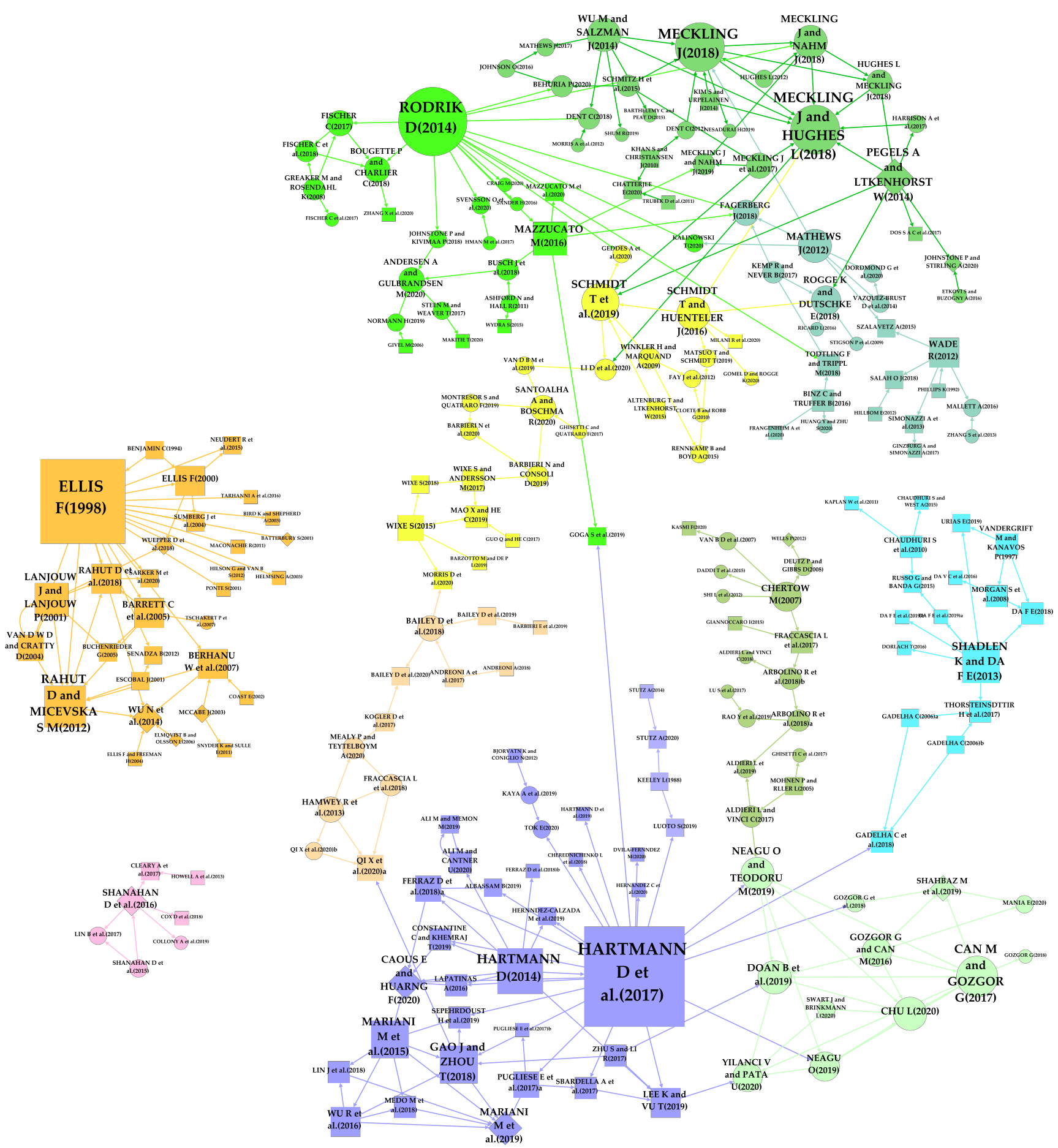

Figure 5. Citation Network. Note: Node color is based on the clusters identified by the Louvain community detection algorithm, node size considers the number of links (local citations), and node shape is based on the sustainability dimension (social, environmental, or both).

The node color is based on the clusters identified through the Gephi class modularity that implements the Louvain Method [66]. The color choices follow the predominant theme in a cluster, considering that: (i) the main cluster covering "Economic Complexity" and "Social Sustainability" is colored blue; (ii) the "Industrial Policy" and "Environmental 
Sustainability" main clusters are colored green; (iii) the "Economic Diversification" and "Environmental Sustainability" is colored yellow; (iv) the "Rural Diversification" and "Social Sustainability" is colored orange. The clusters with a mix of these themes use a variation of these main colors.

The diagram was drawn using Gephi [67] and Cytoscape [68] software, and the citation links were identified using a script programmed in $\mathrm{R}$ version 3.6.3. The clustering was generated through the Gephi class modularity, and the Force Atlas algorithm was chosen for the network layout (in which linked nodes attract each other, while non-linked nodes repel each other).

The network illustrates how the clusters are connected or disconnected from each other. We found 11 clusters distributed among economic complexity, industrial policy, industrial diversification, and rural diversification analyzing social and environmental sustainability. We also found 32 small clusters analyzing 2 or 3 articles, which were not connected with the other articles. These small clusters, as well as articles without any connections inside this network, are not shown in the network representation for visual simplification purposes. The giant purple cluster is responsible for analyzing how economic complexity promotes social sustainability [54,55,69-72]. This cluster is well connected with the light green cluster at the bottom-right of the diagram. These studies analyze how economic complexity affects environmental sustainability $[6,8,9]$, such as the green product space [73]. In addition, this cluster is connected with studies on green product development [74], industrial symbiosis [62], technology spillovers, and water pollution [75]. The social sustainability cluster is connected to the light blue cluster, which investigates the importance of the pharmaceutical sector in developed [76] and developing [57] countries.

The social sustainability cluster is connected with studies on regional sustainability [77] (light orange). Surprisingly, the social sustainability cluster is not well-connected with the industrial policy cluster (bigger green cluster at the top of the figure). Only one study [78] links the economic complexity [54] and industrial policy [37] clusters directly. The green cluster is led by Rodrik's green industrial policy study [21] and the innovation policy study of Mazzucato [37]. Apparently, studies on industrial relatedness [20], the regional diversification of green technologies [19], and employment [79] (yellow cluster), are responsible for connecting economic complexity and industrial policy. The industrial policy cluster focuses on environmental sustainability aspects, and they are well connected with studies on environmental conflicts [60], the role of the developmental state for climate policy [80], policies for innovation [81], and energy transition [56]. Moreover, these studies connect with papers about innovation for sustainability transitions $[82,83]$ and green growth strategies $[58,64]$.

The orange cluster at the mid-left of the diagram refers to rural diversification studies. There is a complementary body of literature studying the importance of rural diversification [41,84], as well as investigations into rural livelihoods in the poor regions of Africa and Asia $[39,40,65]$. This cluster is not connected with economic complexity or industrial policy or industrial diversification studies (yellow cluster). Ellis' paper [39] and others are concentrated on aspects of human development and social sustainability in developing regions of Africa and Asia. Finally, the small pink cluster at the bottom-left of the diagram analyzes the association between urban green spaces, nature relatedness, and health $[63,85]$. Interestingly, the paper of Shanahan et al. [63] combines aspects of social and environmental sustainability. However, this cluster is disconnected from the network. Furthermore, only three publications analyzed social and environmental sustainability in the same research, which suggests that more studies analyzing both social and environmental sustainability would be desirable.

In summary, Figure 5 shows that the economic complexity community is not wellconnected with the industrial policy community, and completely disconnected from rural diversification studies. There is great potential for mutual learning between these clusters. In this study, we concentrated on analyzing studies in these three clusters. We thoroughly analyzed 61 articles according to four requisites: firstly, the central articles of each main 
cluster; secondly, the most cited articles within the network (local citations); thirdly, the articles with an overall high number of citations; and fourthly, articles that analyzed economic diversification and complexity with both social and environmental sustainability considerations at the same time.

\subsection{Main Research Strategies}

This subsection analyzes the main research strategies by dimension and the primary databases and methods used over the years, considering the 61 publications chosen for the in-depth analysis. We divided the reviewed articles into four research-method categories: (i) theoretical-conceptual studies, (ii) empirical-quantitative studies using quantitative techniques to make a general statement about a certain issue using a sample of observations, (iii) empirical-qualitative studies making a more descriptive data analysis or discussing case studies, and (iv) theoretical with quantitative analyses that develop a new theory and test it. Among the research strategies, we found the predominance of theoretical-conceptual studies $(44 \%)$, followed by empirical-quantitative studies (41\%), empirical-qualitative studies $(11 \%)$, and theoretical with quantitative analysis (3\%) (see Figure 6). However, the main research method during the 1990s was theoretical-conceptual (2/3) while only a few papers used empirical-quantitative (1/3) methods. Interestingly, during the 2000s, there was an increasing number of theoretical-conceptual (53\%) and empirical-qualitative (20\%) in absolute terms, and a decreasing number of empirical-quantitative $(20 \%)$ studies. In contrast, the predominant research method from 2010 to 2019 was empirical-quantitative $(55 \%)$, followed by theoretical-conceptual (32\%) and empirical-qualitative $(9 \%)$ research strategies.

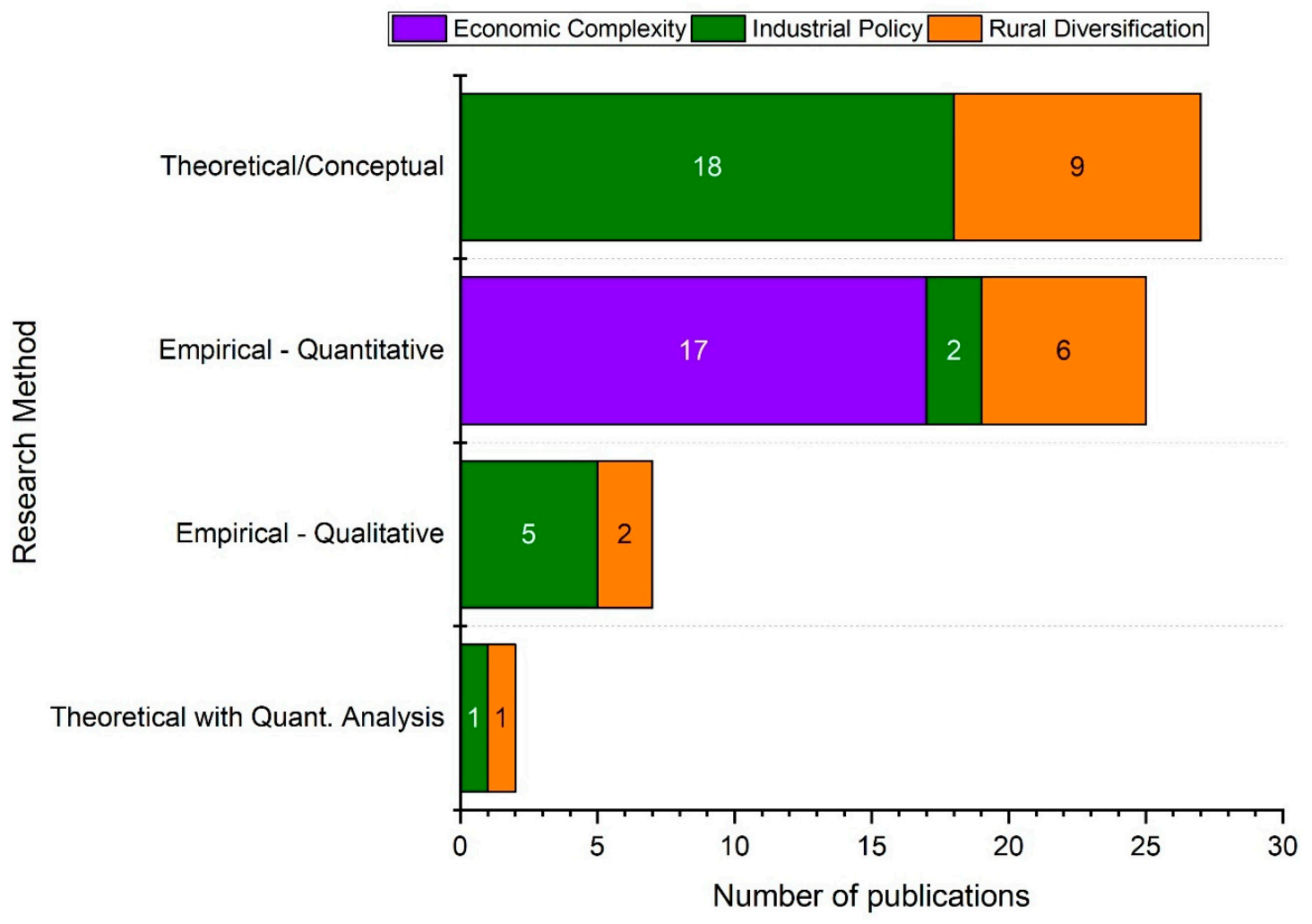

Figure 6. Number of articles according to research method.

The predominance of empirical-quantitative research methods in the last decade is explained by the increasing number of economic complexity studies. However, research on economic complexity tends to omit in-depth conceptual and theoretical considerations. Diversification studies used more empirical, theoretical-conceptual, and quantitative meth- 
ods. Conversely, research on industrial policy mainly used theoretical-conceptual methods. The predominance of qualitative methods for the industrial policy dimension is observed for the period overall.

As can be seen in Figure 7, 44\% of studies used the literature review method. Several studies also used econometrics (31\%), network analysis, method of reflections, the fitness complexity method (7\%), case studies (7\%), and mathematical models (5\%), among others. Economic complexity studies use more advanced methods, since they measure the product space, the relative comparative advantage (RCA), and new indexes. These indexes are used to compare databases and determine their fitness for complexity analysis worldwide. Moreover, several studies have applied these indexes to explain how complexity affects social and environmental sustainability.

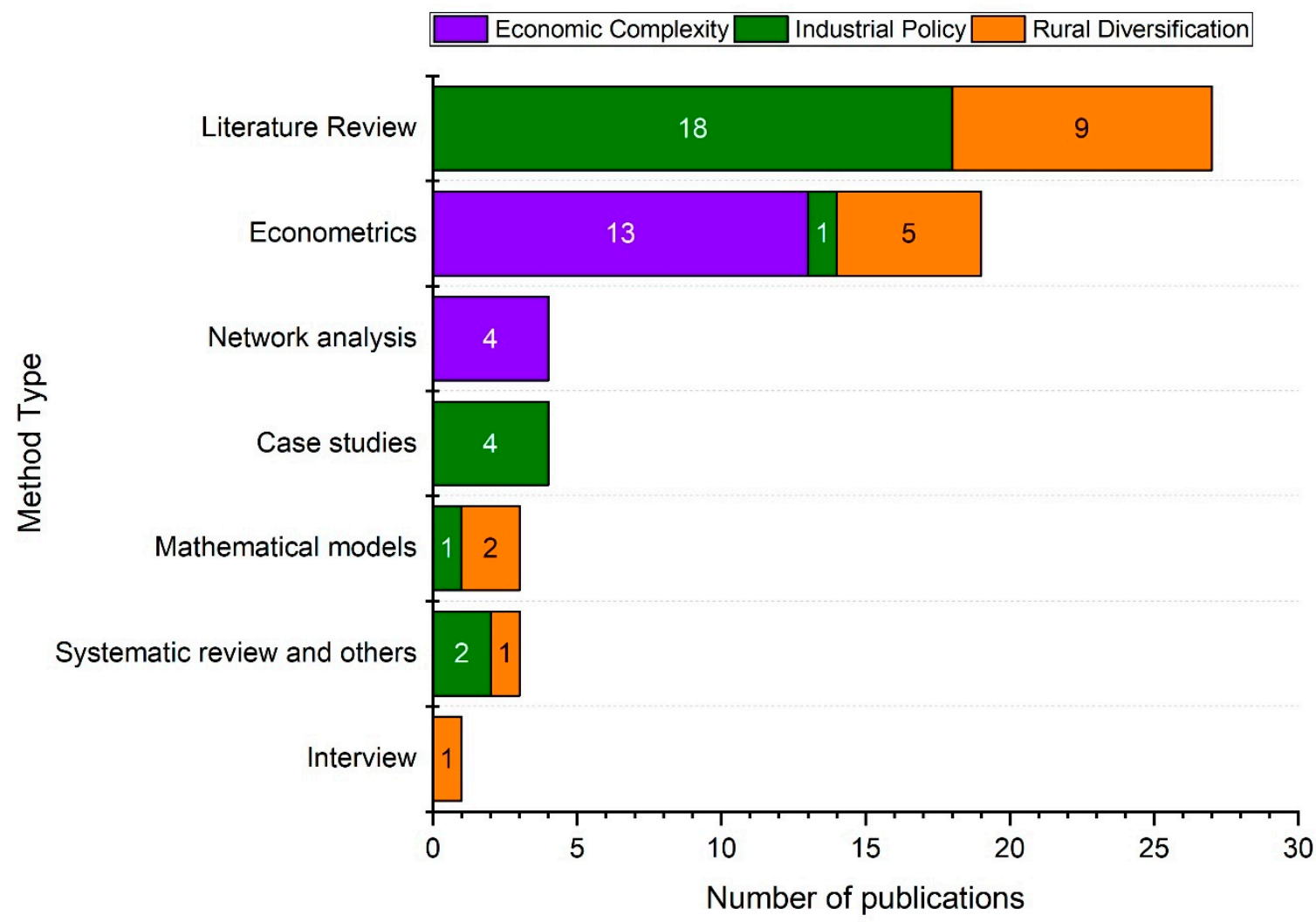

Figure 7. Number of articles according to method type.

While economic complexity develops new quantitative tools, industrial policy usually does not apply new quantitative analysis and data visualization methods. For example, we found five new indicators among the studies analyzed, but all of them were from the economic complexity community. Three indicators (the Complex Index of Relative Development (CIRD) [86], the Product Gini Index (PGI) [54], and complexity and human development [70]) analyze social aspects, and two indicators (Green Product Space [73] and the Similarity Green Product index (SGP) [74]) analyze the sustainability aspect.

The next analysis was based on studies that used at least one database (see Figure 8). This information is important due to the limited number of studies using quantitative methods on industrial policy, and because economic complexity and industrial policy research are somewhat disconnected, implying that they have the potential to learn more from each other. We found that several articles used national databases $(20 \%)$ and primary data $(14 \%)$, such as national censuses [41], sectoral household repositories [65], interviews [87], and surveys $[63,88]$. These studies usually analyze diversification, industrial policy, and nature relatedness dimensions. In contrast, we found that economic complexity studies usually analyze international databases $(66 \%)$, such as United Nations International Trade Statis- 
tics Database (UN COMTRADE) [8,74], Eurostat [16,89], World Bank data [6,9], United Nations data [5,90], and the International Monetary Fund data [9]. It is noteworthy that the Massachusetts Institute of Technology (MIT) provides the Observatory of Economic Complexity repository, which is a broad database with the indexes of 131 countries from 1964 to 2017. Economic complexity research has a comparative advantage over industrial policy and rural diversification, due to the availability of its sizeable databases, which facilitate the application of quantitative empirical methods. Nothing similar exists on the specific industrial policies of countries, or on the diversification strategies of farmers in poor regions.

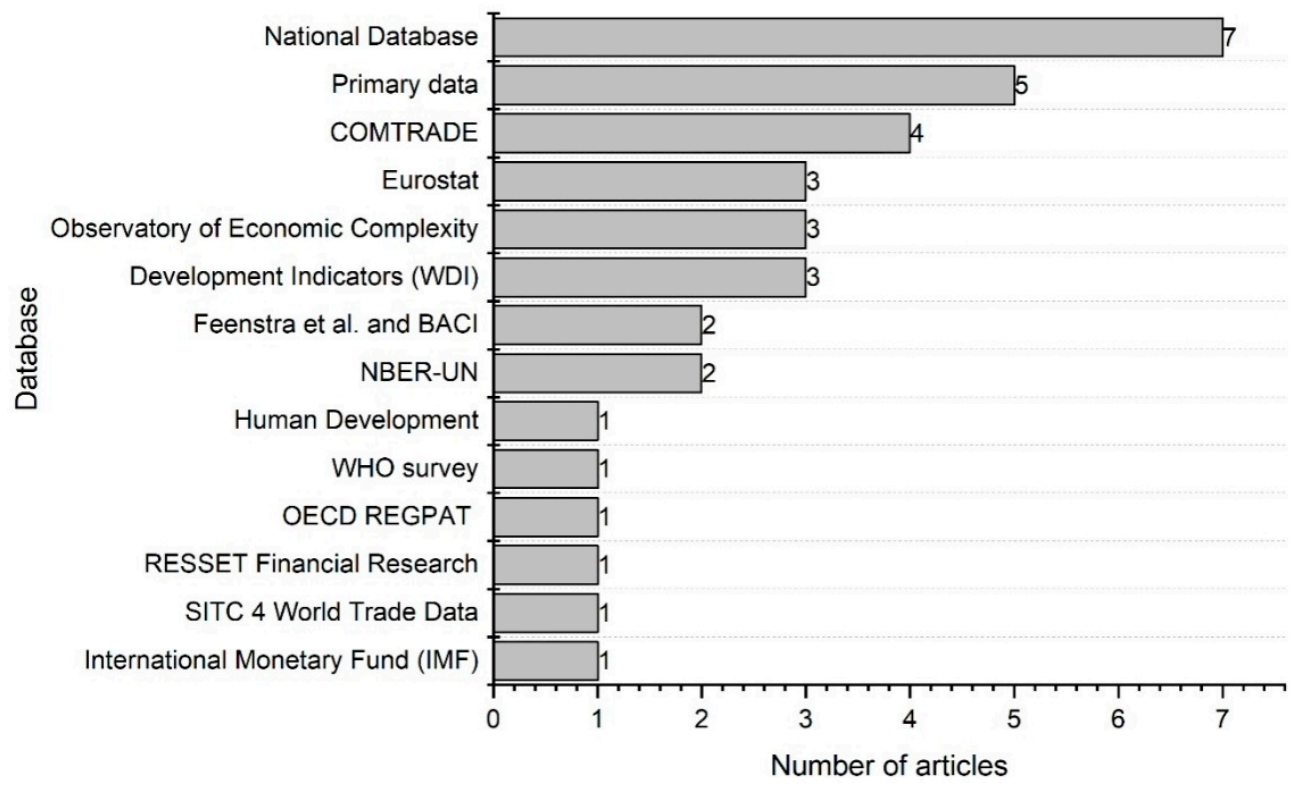

Figure 8. Number of papers per database used.

The main research strategies revealed that economic complexity offers a better set of techniques to evaluate its impact on social and environmental issues. Using advanced methods to create indicators and measure econometric models, this approach involves an increasing number of studies exploring different areas, such as inequality, human development, $\mathrm{CO}_{2}$ emissions, and green products. In contrast, industrial policy continues to use theoretical-conceptual analysis, making the provision of straightforward policy implications more challenging. In addition, rural diversification uses quantitative and qualitative methods, although the rural livelihood approach does not usually employ more advanced techniques. It is noteworthy that the discrepancy between research strategies can partially be explained by the absence of respective databases that allow for the application of sophisticated empirical methods.

\subsection{Scope Analysis}

In this subsection, we analyzed the papers according to their scope of geographical region, units analyzed and sustainability sub area. Table 2 presents the distribution of the 61 articles selected for the in-depth analysis. Firstly, there is an equal number of articles on economic complexity and diversification (17 and 18 articles, respectively) and slightly more studies on industrial policy ( 26 articles) in the identified key articles. Moreover, the economic complexity community has a slightly higher number of papers on environmental $(53 \%)$ than social (41\%) sustainability, and only one study $(6 \%)$ that analyzed both areas. In contrast, the rural diversification community focused on social issues (72\%), while environmental sustainability received less attention (6\%). Surprisingly, however, four studies were found (22\%) using both social and environmental sustainability. Finally, the industrial policy dimension concentrates its efforts on environmental sustainability 
$(65 \%)$, rather than on social aspects $(27 \%)$, and only two studies $(8 \%)$ were identified which combined both areas.

Table 2. The number of publications chosen for the in-depth analysis for each dimension/area.

\begin{tabular}{ccc}
\hline Dimension/Area & Publications & \% \\
\hline Complexity & & 53 \\
\hline Environmental Sustainability & 9 & 41 \\
Social Sustainability & 7 & 6 \\
Both & 1 & 100 \\
Total & 17 & \\
\hline Rural Diversification & & 6 \\
Environmental Sustainability & 1 & 72 \\
Social Sustainability & 13 & 22 \\
Both & 4 & 100 \\
Total & 18 & 65 \\
\hline Industrial Policy & & 27 \\
\hline Environmental Sustainability & 17 & 8 \\
Social Sustainability & 7 & 100 \\
Both & 2 & 100 \\
Total & 26 & \\
\hline Total & 61 & \\
\hline
\end{tabular}

We also systematized the social and environmental sub areas that were most analyzed. Table 3 summarizes these results. We found that most papers on social sustainability also considered economic topics associated to inequality, poorer strata and regions (61\%), such as employment and income in the rural non-farm sector [61,84] and tourism diversification [84], and economic inequality aspects [54,55,69]. Health $(16 \%)$ is the second most frequent sub area, mainly because of the need for industrial policy to promote the pharmaceutical sector, especially in developing countries [57,76,91]. Equally frequent, most studies on education (16\%) are associated with occupation relatedness [20], industrial policy [92], and rural diversification considerations [41,93]. Only one study analyzed the effect of complexity on secondary and tertiary education levels [71]. Furthermore, few studies $(8 \%)$ analyzed several aspects of social sustainability $[55,70]$. Arguably studies on social sustainability should also explore other dimensions, such as gender inequality and basic infrastructure.

Studies on environmental sustainability tended to analyze $\mathrm{CO}_{2}$ or Greenhouse gas emissions (GHG) $[6,8,9,16]$ or water pollution [75] (48\%). However, we did not find studies investigating ecological footprints and other emission types, such as sulfur dioxide $\left(\mathrm{SO}_{2}\right)$ pollution. Several studies analyze ecosystem services and nature relatedness $(19 \%)[63,85]$. Other studies focus on green spaces [73], green products [74], eco-industry [94] (13\%). In contrast to studies on social sustainability, few studies focus on economic aspects, such as green jobs and income $(10 \%)[79,94]$. Moreover, even fewer studies focus on energy transition [95] and low carbon energy (10\%) [59].

Figure 9 illustrates the units analyzed in 46 of the 61 studies (since 15 studies were of a general nature or related to areas classified as "not applicable"). We found that 30 articles $(65 \%)$ analyze countries. The abundance of information explains most studies analyzing countries in international databases [52]. The unequal data availability for different countries, though, leads to lack of insights on countries with less data. Moreover, the conceptual-theoretical studies on industrial policy focus on developed countries and emerging economies, which usually have more data. Economic complexity studies are so far dominated by quantitative research on the country level. Most of the rural diversification studies, on the other hand, have a more general scope. Furthermore, a few studies analyze cities $(7 \%)$, regions $(7 \%)$, case studies $(4 \%)$, and the individual level analysis (4\%), among 
others. The studies analyzing the individual level analysis investigate green urban spaces and nature relatedness $[63,85]$.

Table 3. Classification of the major social and sustainable sub areas.

\begin{tabular}{|c|c|c|c|c|c|}
\hline Social Sustainability & Papers & $\%$ & $\begin{array}{l}\text { Environmental } \\
\text { Sustainability }\end{array}$ & Papers & $\%$ \\
\hline $\begin{array}{l}\text { Economic aspects (employment, income, and } \\
\text { others), especially of poor strata, poor regions, or in } \\
\text { association with inequality }\end{array}$ & 23 & 60.53 & $\begin{array}{l}\text { Emissions }\left(\mathrm{CO}_{2}, \mathrm{GHG}\right) \text { and } \\
\text { Water pollution }\end{array}$ & 15 & 48 \\
\hline Health & 6 & 15.79 & $\begin{array}{l}\text { Environment, Biodiversity, } \\
\text { ecosystem services, } \\
\text { nature relatedness }\end{array}$ & 6 & 19 \\
\hline Education & 6 & 15.79 & $\begin{array}{l}\text { Green spaces, green } \\
\text { products, Eco-Industry }\end{array}$ & 4 & 13 \\
\hline \multirow{2}{*}{$\begin{array}{l}\text { Several aspects of social sustainability (education, } \\
\text { economic, health, infrastructure) }\end{array}$} & \multirow{2}{*}{3} & \multirow{2}{*}{7.89} & Economic aspects & 3 & 10 \\
\hline & & & $\begin{array}{l}\text { Energy transition, low } \\
\text { carbon energy }\end{array}$ & 3 & 10 \\
\hline Total & 38 & 100.00 & Total & 31 & 100 \\
\hline
\end{tabular}

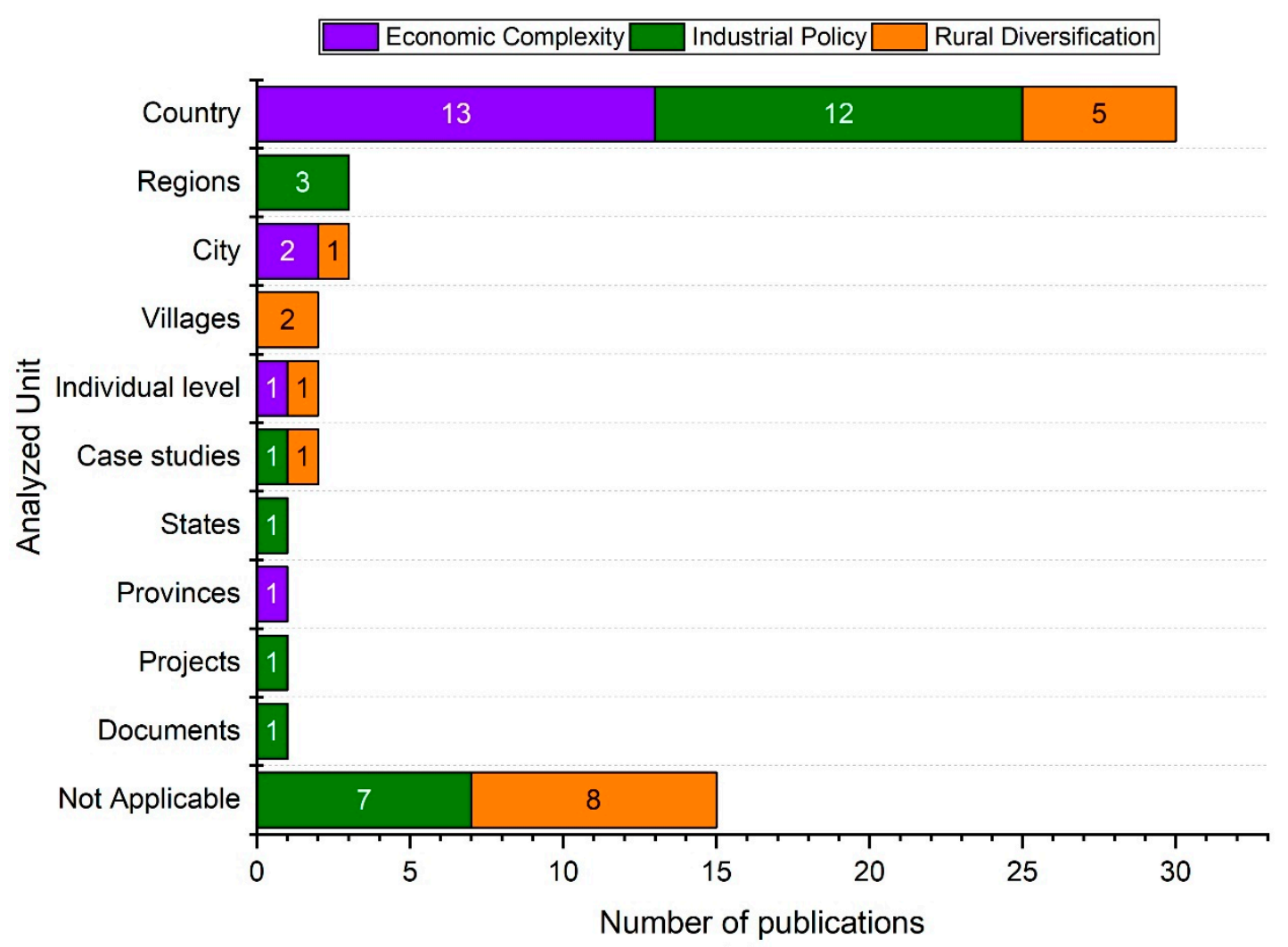

Figure 9. Classification by analyzed units.

Figure 10 summarizes the geographical focus of the 61 articles selected. We found that most of these studies focus on Europe (26\%) or a global analysis (20\%). Europe was studied by the three research areas, but with a predominance of studies on economic complexity and industrial policy. The worldwide studies are similarly dominated by economic complexity, but studies on economic diversification in rural areas also appear. On the other hand, the three studies from Africa focused on diversification in rural areas. Several studies analyzed countries in Asia (11\%), North America (9\%), Africa (7\%), and Oceania (7\%). 
Other studies combined intercontinental evaluation, such as Asia and Africa (4\%), and Europe and North America (4\%). Few studies evaluated South America $(4 \%)[57,73]$ and Latin America (2\%) [70]. Studies analyzing Europe provided information about Turkey [9], as well as complexity in European Union countries [8], France [6], energy transition in Germany [56], the developmental state and climate change [80], industry relatedness and education [20], and diversification [41]. A total of two studies from Australia (thus Oceania) investigated nature relatedness and health conditions in the city of Brisbane $[63,85]$, and another study investigated industrial symbiosis in two Australian regions (Kwinana and Gladstone) [96]. We did not find studies analyzing nature relatedness and health conditions in other countries. Several studies analyzed rural livelihood diversification in Africa and Asia [39,40,65,93]. Only one study analyzed Latin America [70], comparing it with countries in Asia in terms of the complexity dimension.

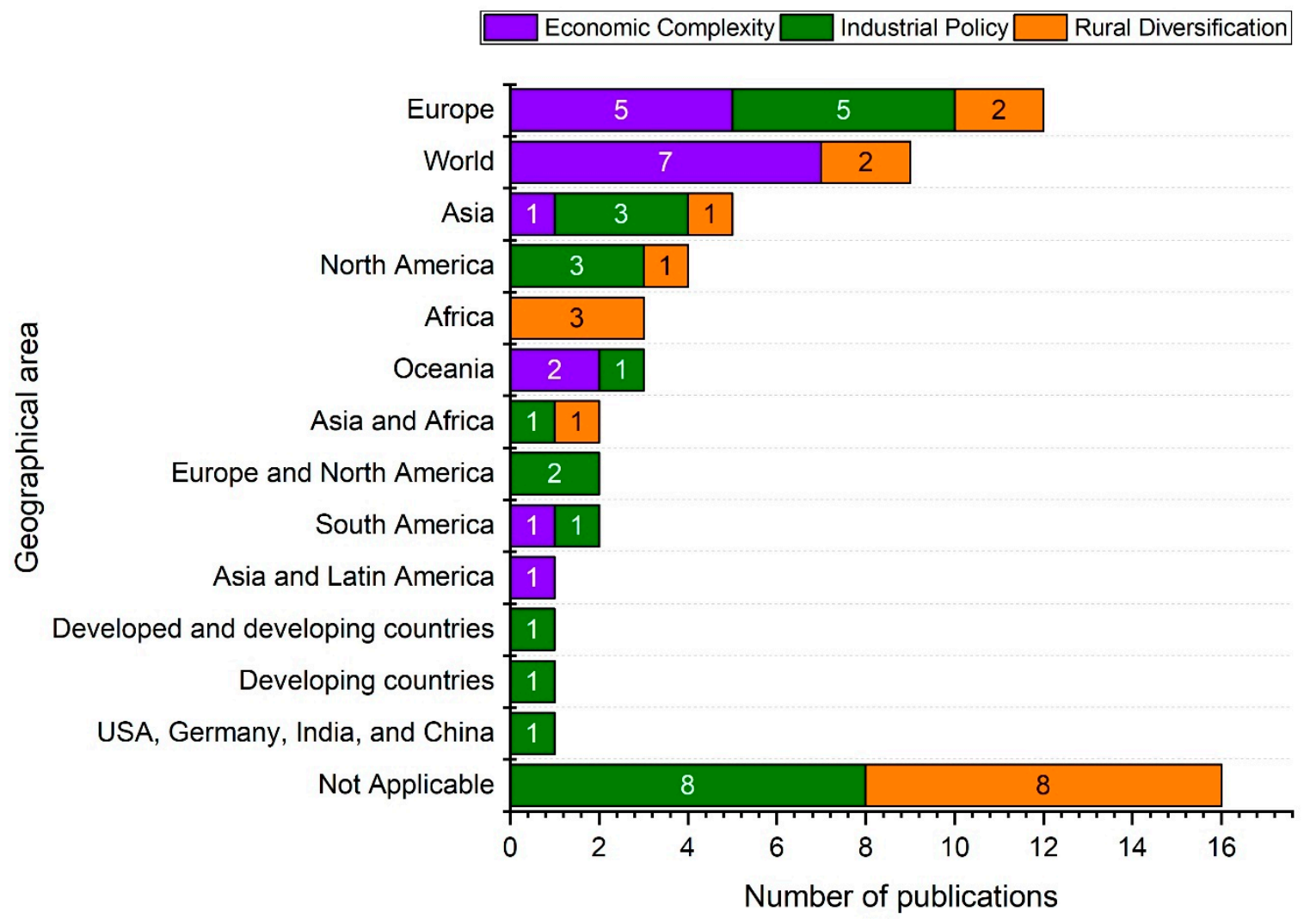

Figure 10. Classification by geographical area.

This subsection shows our classification system analysis. We observed that some geographical areas and regional analyses require more attention, since few studies have been applied to them. Additionally, although social and environmental sustainability are present in a number of papers, some subareas are underdeveloped or even completely missing. Moreover, alternative measures to evaluate environmental sustainability are required, such as applications using ecological footprints and other types of pollutant emissions than $\mathrm{CO}_{2}$ and GHG.

\section{Discussion of Main Arguments and Findings}

This section discusses the literature on economic complexity, industrial policy, and rural diversification in association with social and environmental sustainability. Here, we highlight the main studies and elaborate on some limitations, political implications, and future research recommendations. 


\subsection{Economic Complexity}

Social and environmental sustainability studies have been using economic complexity as a strategy to promote sustainable development. With regard to social sustainability, studies from the economic complexity community have investigated the effect of economic complexity on inequality [54], human capital [71], and human development [70]. Some authors show a strong, robust, and stable correlation between a country's economic complexity level and its level of income inequality [3,54], and a lateral escape from the poverty trap [86]. Furthermore, Zhu and Li [71] found that complexity positively impacts both secondary and higher education in long- and short-term growth. In other words, these studies found that economic complexity substantially reduces inequality and boosts human capital and human development worldwide. The main argument is that complex productive structures require more inclusive institutions with a better distribution of political and economic power, and better educated, well-paid, and empowered workers, who have a more comprehensive range of job choices [46]. In this sense, these studies demonstrate alternative ways for policymakers to develop their policies, using economic complexity as a tool to provide better living conditions. However, research on economic complexity and social sustainability has been criticized for not fully demonstrating a causal relation [3] nor providing robust time-series evidence [72] linking economic complexity and development. Moreover, several authors have argued that future studies should focus on several econometric aspects, such as more robust panel data using advanced econometric techniques and statistical tests (threshold models, instrumental variables, and endogeneity tests, among others) $[72,86]$. Furthermore, studies investigating the association between industrialization and gender equality, as well as the association between different types of knowledge and the country's productive matrix, are required [54].

In regard to environmental sustainability, several studies have analyzed the role of economic complexity to reduce $\mathrm{CO}_{2}$ and greenhouse gas emissions [6-9,16], and to create green product spaces $[73,74]$. These studies argue that innovation and technological products reduce energy consumption by using alternative sources and creating environmentally friendly products, such as photovoltaic cells, wind turbines, and electric cars, among others $[8,16]$. In other words, economic complexity is useful for decision- and policy-makers because it presents several benefits, such as managing pollution control [7], to provide an adequate environment for energy transition [16], and to boost economic growth while reducing the environmental impact [22]. Using green product spaces can enable authorities to target specific sectors to prioritize products with a reduced environmental impact [73,74]. Moreover, companies can use economic complexity to concentrate investments in products that do not affect the environment, and accumulate the capabilities required to produce green products [16]. Furthermore, studies on economic complexity and environmental sustainability may also better explore emerging economies [6], use data from both domestic and export production, apply dynamic analysis (instead of the static comparative advantage of countries), create a clear definition and classification of green products [73,74], apply alternative econometric techniques (such as time series analysis for a specific country or country groups), and consider structural breaks [7].

It must be noted that there are recent studies on the relationship between economic complexity, relatedness, and industrial policy with environmental sustainability that did not enter into our core articles dataset and in-depth analysis because they did not (yet) match our method protocol and threshold criteria of being peer-reviewed or already being in the WoS or Scopus database and having a minimum number of citations. However, due to their high relevance and quality, we briefly summarize their main findings subsequently. Lapatinas et al. [97] found that economic complexity is associated with a better environmental performance, in terms of the Environmental Performance Index, in 88 developed and developing countries; however, the authors also found robust evidence that complexity decreases air quality and increases $\mathrm{CO}_{2}$ emissions. In contrast, Romero and Gramkow [23] found that economic complexity decreases greenhouse gas emission intensity and per capita emissions. Moreover, they contribute to the literature by proposing 
the Product Emission Intensity Index (PEII), which shows that sophisticated products reduce emission intensities. Mealy and Teytelboym [98] developed a new method for measuring productive capabilities for the green economy. Their method revealed that top-ranked countries (e.g., Germany, Italy, United States, Austria, Denmark) have higher environmental patenting rates, lower pollutant emissions, and more environmental policies. Huberty and Zachmann [99] investigated the effect of green industrial policy on the export market competitiveness. The authors found evidence that green industrial policy influences wind turbine exports, but it does not affect the exports of solar cells. Montresor and Quatraro [100] investigated smart specialization and green diversification in 240 European regions. The authors found that relatedness helps to promote green diversification, mostly due to pre-existing green knowledge. Perruchas et al. [101] investigated the geographical distribution of green technology. They found that green diversification depends on available competencies and cumulative paths influence the specialization patterns and ability of countries to move into more mature green technologies. This type of papers on complexity and green growth are likely to expand in the near future, gain in citations, enter the academic databases, and form a significant research community.

Despite the expanding recent literature, it is noteworthy that there is no study comparing the effects of economic complexity on both social and environmental sustainability in the databases. This, though, could be useful to understand how economic complexity can help sustainability in a broader sense. For example, current economic complexity research does not explain well whether economic complexity changes consumer preference for green products while improving their skills and income. Moreover, the literature does not explain whether economic complexity-caused urbanization processes may increase environmental degradation.

\subsection{Industrial Policy}

According to Rodrik [21], industrial policy plays a crucial role in putting the global economy on a green growth path. In this sense, industrial policy must provide new technologies that generate positive spillovers, externalities between firms, new skills, and agglomeration effects $[21,29,37]$. For example, Germany's energy transition case for solar photovoltaic and wind energy is considered a successful example of how to implement world-class renewable energy technologies, which guarantee competitiveness, employment, and a positive process of innovation [56]. East Asian countries (Japan, South Korea, Taiwan, and China) have observed the power of industrial policy to promote development. For example, South Korea developed a green growth strategy to create alternative ways to boost economic growth, job creation, and exports, instead of only focusing on costs [58]. China's eco-industrial development promotes its strategy based on policies, laws, regulations, and financing by entrepreneurs and the public sector [102]. In this sense, some authors advocate industrial policy as a tool to support global regulatory leadership and global regulatory cooperation. Certainly, the developmental state influences climate governance according to its global competitiveness [80].

It is clear that the green growth strategy requires careful policy sequencing to reduce emissions under political constraints. Effective industrial policy requires a better connection between the economic and political agendas, instead of policies focusing only on efficient pricing [103]. This is especially crucial for developing countries, where long-term green growth vision and a clear roadmap, which reduces the transition efficacy to promote innovation and investments, remain unclear. This includes policy measures aiming at institutional capabilities, skills, and job creation [95]. However, industrial policy still faces criticisms regarding its efficacy in promoting development in developing countries, such as in Latin America [21].

Some studies of the industrial policy approach have focused on the importance of the pharmaceutical sector [57,91]. Such studies argue that industrial policy is crucial to guarantee independence through innovation and patents for medicines, encouraging the health industry in developing countries. These countries can promote health by using 
policy interventions, such as industrial protection and active government purchasing, legislative and regulatory instruments, training programs, and mechanisms to promote joint ventures [91]. These programs must be led by the state, integrating industrial and health policies. For example, Brazil presents a positive synergy between health policy and industrial policy. This is due to the demand-driven and regulation-induced characteristics of the pharmaceutical sector, which requires state intervention through industrial policy. Moreover, industrial policy must focus on the specific needs and demands of the health sector, in order to achieve better outcomes [57].

The industrial policy approach is more focused on environmental sustainability than on social sustainability. While several studies analyzed how industrial policy affects the environment, few studies have investigated the impact of industrial policy on health. Moreover, we did not find studies analyzing the impact of industrial policies on other aspects of social sustainability, such as education, gender inequality, or well-being. This suggests that future studies on industrial policy might need to focus on social dimensions to understand sustainability better.

\subsection{Economic Diversification in Rural Areas}

According to the seminal study of Ellis [39], rural diversification investigates the survival and income strategies of individuals and families in rural areas of developing countries. This approach is vital, since these rural areas suffer from low incomes and precarious conditions. Yet diverse livelihood approaches reduce the vulnerabilities of rural families, by managing seasonality, risk, and market failures [41]. Indeed, the rural diversification community advocates for policymakers to facilitate rather than inhibit rural diversity by promoting mobility, access to information, micro-credit, rural services, rural non-farm enterprises, rural towns, better infrastructure, and access to education, thereby reducing barriers and bureaucracy for small-scale businesses [40]. Livelihood strategies help to create non-farm income sources, especially for skilled workers, who can receive higher income and greater job mobility outside of the traditional rural sector. On the other hand, less diverse households without access to non-rural activities or insufficient assets (i.e., land and livestock) are more vulnerable and dependent on traditional agricultural means. These households face a dynamic poverty trap, since poor workers tend to be engaged in agricultural activities $[65,88]$. Other factors also play a crucial role in promoting rural diversification, such as education, farm size, and geographical location. Education is important if the skills required to transfer workers to non-farm activities are to be developed [93]. Farm size may provide high profitability returns for non-farm sectors, although farm size is not necessarily a constraint to diversification. The geographical location of farms shows the importance of the local context on rural diversification [88]. For example, Cyprus developed agritourism, but now faces low returns, low demand, and a lack of essential skills to adequately promote it. The dominance of traditional tourism over the island's summer-sun destinations may be discouraging agritourism in rural areas, suggesting that policymakers should consider providing subsidies and support for rural tourism [84].

It is noteworthy that rural diversification studies tend to be focused on social sustainability rather than on environmental sustainability. Better living conditions (income, employment, labor mobility, necessary infrastructure, education, and health) are discussed, but no emphasis is put on the importance of environmental sustainability, such as reducing pollutant emissions, providing green products, sustainable tourism and activities commanded by small businesses. In this sense, future studies on the rural diversification approach have several opportunities for considering environmental sustainability aspects.

\section{Literature Gaps}

The systematic literature review of this study uncovered multiple avenues for future studies on economic complexity, industrial policy, and rural diversification in association 
with social and environmental issues. Indeed, our analysis revealed 4 research macrogaps, which are divided in 13 research gaps. These gaps are summarized in Table 4.

Table 4. Gaps of the literature.

\begin{tabular}{|c|c|}
\hline Category & aps \\
\hline Theory & $\begin{array}{l}\text { G1. Absence of studies interconnecting economic complexity, rural diversification, and industrial policy. } \\
\text { G1a. A very limited number of studies have analyzed social and environmental sustainability together. } \\
\text { G1b. The rural diversification community (surprisingly) shows an absence of studies on environmental } \\
\text { sustainability. } \\
\text { G1c. The industrial policy community tends to omit social sustainability aspects (assumes positive effects, but does } \\
\text { not explore them in more detail). } \\
\text { G1d. Economic complexity research seldom discusses development theories or industrial policies in more detail. } \\
\text { G1e Research on industrial policy seldomly cites works on economic complexity or makes use of its new methods. }\end{array}$ \\
\hline $\begin{array}{l}\text { Missing } \\
\text { topics }\end{array}$ & $\begin{array}{l}\text { G2. The literature does not adequately discuss some of the dimensions of social and environmental sustainability. } \\
\text { G2a. Potential for new studies on economic complexity might focus on health, institutions, gender and race } \\
\text { inequality, infrastructure, occupations, and skills. } \\
\text { G2b. Research on environmental sustainability in the sample did not consider ecological footprints and alternative } \\
\text { types of pollutant emissions. }\end{array}$ \\
\hline Data & $\begin{array}{l}\text { G3. There are no global available databases providing information for rural diversification and industrial policy. } \\
\text { G3a. There are relatively few studies analyzing regional data within a country. } \\
\text { G3b. Only a limited number of studies have analyzed Africa using the economic complexity approach in association } \\
\text { with sustainability considerations. } \\
\text { G3c. There is a concentration of studies analyzing green urban spaces, nature relatedness, and health conditions in } \\
\text { Australia, though these topics are relevant for many other countries as well }\end{array}$ \\
\hline Method & $\begin{array}{l}\text { G4. There is a need for a more balanced mix of research methods in each research community. } \\
\text { G4a. A very limited number of economic complexity studies have made use of theoretical/conceptual } \\
\text { research strategies. } \\
\text { G4b. Econometric studies on economic complexity should involve a more thorough discussion of statistical and } \\
\text { econometric issues (such as endogeneity, time lags, instrumental variables, and autocorrelation), especially with } \\
\text { regard to the social sustainability dimension. } \\
\text { G4c. A very limited number of studies have made use of empirical quantitative methods analyzing industrial policy. }\end{array}$ \\
\hline
\end{tabular}

Firstly, there are only few studies linking the three main clusters with each other and linking social and environmental sustainability theoretically. Such studies would help to better understand the relationship between social issues (e.g., inequality and human development) and ecological issues and would be fundamental to develop adequate policy recommendations worldwide. Furthermore, the systemic literature review suggests that the rural diversification community insufficiently focuses on environmental sustainability aspects. This gap might be addressed by learning with studies that analyze economic complexity and environmental issues $[7,8,16,22,23]$. For example, the study "The impact of economic complexity on carbon emissions" [6] could be a starting point to give insights of how rural areas could diversify their economic activities and at the same time reduce environmental impacts of their current economic activities. Moreover, the literature review suggests that the industrial policy community insufficiently focuses on social sustainability, which could be addressed by linking to research on complexity and social issues [54,55,69-71,104]. For example, the study "Linking Economic Complexity, Institutions, and Income Inequality" [54] could be a starting point to show the links between complexity and social aspects, which could be used by other research communities.

Secondly, according to the findings in our literature review, some social and environmental sustainability dimensions have not been explored comprehensively. For example, only a limited number of studies have analyzed the impact of economic complexity on health, institutions, gender and race inequality, infrastructure, occupations, and skills. For instance, future studies could explore the impact of economic complexity on specific diseases (e.g., mental illnesses), democracy and the quality of public services, or discrepancies of salary between men and women or white and black people in developing regions or ad- 
equate infrastructure for logistic services (e.g., roads, railways, ports, and airports), among others. However, these new insights might require theoretical foundations, which might be filled using related studies on the industrial policy and rural diversification communities. Additionally, we did not find studies analyzing ecological footprints and pollutants other than $\mathrm{CO}_{2}$ emissions. These studies may show the impact of complexity on alternative fields, which is important for policy implications related to social and environmental sustainability.

Thirdly, to our best knowledge, the industrial policy and rural diversification community cannot make use of worldwide national and regional databases, such as economic complexity and relatedness research. The development of such databases could also focus on regional information, which is fundamental for enlarging the set of potential success and failure cases of industrial policies in developing and emerging economies, applying empirical tests and formulating region-specific policies.

Fourthly, there are discrepancies in the methods adopted by the three main clusters. For example, the industrial policy community could make use of methods from relatedness and economic complexity research to understand development traps, constraints and opportunities for economic catch-up and leap-frogging ahead [31]. Moreover, rural diversification community could develop econometric models to analyze how diversification affects livelihoods. Both communities lack studies creating indicators and making use of methods from data visualization, which can be useful tools for knowledge transfer and debate with decision and policymakers.

\section{Conclusions}

This paper reviewed studies on economic complexity, industrial policy, and rural diversification in association with social and environmental sustainability. We also used the systematic literature review technique to analyze the principal studies in this field. We found several clusters in the research network. However, three burgeoning dimensions caught our attention because they show considerable potential for mutual learning and knowledge exchange about the associations between economic diversification and complexity, and social and environmental sustainability.

The first economic complexity approach focuses on quantitative methods, but it lacks theoretical and conceptual studies. In this sense, the economic complexity community might learn from the theoretical background and applied policy considerations of the industrial policy community, providing a better understanding of the relationship between the complexity of productive structures and social and environmental sustainability. Moreover, the economic complexity community may also further explore diversification and sophistication processes and opportunities in less developed regions.

Second, industrial policy mostly uses theoretical and conceptual methods, but it fails to apply quantitative techniques that provide robust empirical support. For this reason, the industrial policy community could learn from the economic complexity community to develop new indicators for providing empirical results to support political action.

Third, the research community focusing on economic diversification in rural, poor areas uses theoretical and quantitative analysis, but it does not analyze the importance of technology to reduce social and environmental vulnerability in the rural sector. Thus, the rural diversification community might use the arguments of economic complexity to improve links with the industrial policy communities, develop new strategies and provide better living standards in rural areas. The latter, though, also requires the efforts of the industrial policy community, which tends to omit the agriculture sector as being a less desirable sector. Yet it may run the risk of "throwing out the baby with the bathwater" in developing and emerging economies, in which rural activities constitute an essential economic base for billions of people.

It is hoped that some limitations of the study here presented might open opportunities for future research in this emerging research field. First, although the study used a wide range of 35 keywords, future studies are encouraged to examine the literature using an 
alternative protocol, for example exploring the 17 Sustainable Development Goals (SDGs). Nonetheless, it must be noted that while the general idea of the broadly framed SDG have been praised for their increased focus on ecological sustainability in comparison with previous general frameworks (like the Millennium development goals or the human development approach) they also have been criticized for issues of inconsistency, measurability and monitoring [105]. Indeed, subsequent reviews may scrutinize and discuss keywords for the association of economic diversification with each of the 17 SDG, as well as the interaction between the different goals, and thus help to address potential inconsistencies and measurability issues. Second, future researchers could also examine the core literature in other languages, such as Chinese, Spanish, French, or Japanese. Third, the empirical results presented several clusters, but we only focused on the three main clusters in detail. Perhaps, future studies could scrutinize other emerging clusters. It is likely that many of the smaller clusters may grow and connect to existing research communities. Fourth, future studies could analyze rural diversification in more depth, since this literature is essential for economic development in poor regions. Fifth, future studies could use other techniques, such as main path analysis, to compare findings. Sixth, future research could investigate (in depth) other papers which are not part of the 61 articles read in our study.

It is noteworthy to mention that, in the next few years, many new articles dealing with economic complexity and environmental pollution, inclusive growth, regional characteristics, sustainable development goals (SDG), or intersectionality topics are likely to emerge and be found in the databases on peer-reviewed articles. Undoubtedly, this rapidly growing research can be explored in future reviews. However, as new research fields have a context and a "history", it is important to address (apparently) parallel research fields, understand their strengths and how they can learn from each other and work together. Lastly, future reviews may find alternative gaps, as new works are being added to the publication databases.

Nonetheless, what is clear from this structured literature review is that research linking economic diversification, economic complexity, and industrial policies with social and environmental sustainability is rapidly growing, though this is still rather fragmented with several research groups working separately. The research communities centered on economic complexity, rural diversification, and industrial policies respectively are working on related topics and are creating new insights to promote social and environmental sustainability. However, they still rarely cite and learn from each other. In this sense, there is great potential for mutual learning between these topic-related research communities for the sake of sustainable development.

Author Contributions: Conceptualization, D.H. and D.F.; methodology, E.B.M. and F.P.S.F.; software, F.P.S.F.; validation, D.F. and D.H.; formal analysis, D.F. and F.P.S.F.; investigation, D.F.; results, D.F. and D.H.; writing—original draft preparation, D.F. and F.P.S.F.; writing—review and editing, D.H.; supervision, D.H. All authors have read and agreed to the published version of the manuscript.

Funding: This research received no external funding.

Institutional Review Board Statement: Not applicable.

Informed Consent Statement: Not applicable.

Data Availability Statement: Data sharing not applicable.

Conflicts of Interest: The authors declare no conflict of interest.

\section{References}

1. Hidalgo, C.A.; Klinger, B.; Barabasi, A.L.; Hausmann, R. The product space conditions the development of nations. Science 2007, 317, 482-487. [CrossRef]

2. Hidalgo, C.A.; Hausmann, R. The building blocks of economic complexity. Proc. Natl. Acad. Sci. USA 2009, 106, 10570-10575. [CrossRef]

3. Gao, J.; Zhou, T. Quantifying China's regional economic complexity. Phys. A Stat. Mech. Appl. 2018, 492, 1591-1603. [CrossRef] 
4. Hausmann, R.; Hidalgo, C.A.; Bustos, S.; Coscia, M.; Simoes, A.; Yildirim, M.A. The Atlas of Economic Complexity: Mapping Paths to Prosperity; MIT Press: Cambridge, MA, USA, 2014.

5. Mariani, M.S.; Vidmer, A.; Medo, M.; Zhang, Y.-C. Measuring economic complexity of countries and products: Which metric to use? Eur. Phys. J. B 2015, 88, 293. [CrossRef]

6. Can, M.; Gozgor, G. The impact of economic complexity on carbon emissions: Evidence from France. Environ. Sci. Pollut. Res. 2017, 24, 16364-16370. [CrossRef] [PubMed]

7. Doğan, B.; Saboori, B.; Can, M. Does economic complexity matter for environmental degradation? An empirical analysis for different stages of development. Environ. Sci. Pollut. Res. 2019, 26, 31900-31912. [CrossRef] [PubMed]

8. Neagu, O. The Link between Economic Complexity and Carbon Emissions in the European Union Countries: A Model Based on the Environmental Kuznets Curve (EKC) Approach. Sustainability 2019, 11, 4753. [CrossRef]

9. Gozgor, G.; Can, M. Export product diversification and the environmental Kuznets curve: Evidence from Turkey. Environ. Sci. Pollut. Res. 2016, 23, 21594-21603. [CrossRef]

10. Rodrik, D. Policies for Economic Diversification. Cepal Review. 2005. Available online: https://repositorio.cepal.org/bitstream/ handle/11362/11111/1/87007023I_en.pdf (accessed on 25 January 2021).

11. Agosin, M.R. Export Diversification and Growth in Emerging Economies. Cepal Review. 2009, pp. 115-131. Available online: https:/ / repositorio.cepal.org/bitstream/handle/11362/11322/97115131I_en.pdf (accessed on 25 January 2021).

12. Boschma, R.; Iammarino, S. Related variety, trade linkages, and regional growth in Italy. Econ. Geogr. 2009, 85, 289-311. [CrossRef]

13. Boschma, R.; Minondo, A.; Navarro, M. Related variety and regional growth in Spain. Pap. Reg. Sci. 2012, 91, 241-256. [CrossRef]

14. Alshamsi, A.; Pinheiro, F.L.; Hidalgo, C.A. Optimal diversification strategies in the networks of related products and of related research areas. Nat. Commun. 2018, 9, 1-7. [CrossRef] [PubMed]

15. Hidalgo, C.A.; Balland, P.-A.; Boschma, R.; Delgado, M.; Feldman, M.; Frenken, K.; Glaeser, E.; He, C.; Kogler, D.F.; Morrison, A. The principle of relatedness. In International Conference on Complex Systems; Springer: Cham, Switzerland, 2018; pp. 451-457.

16. Neagu, O.; Teodoru, M.C. The relationship between economic complexity, energy consumption structure and greenhouse gas emission: Heterogeneous panel evidence from the EU countries. Sustainability 2019, 11, 497. [CrossRef]

17. Boschma, R. Proximity and innovation: A critical assessment. Reg. Stud. 2005, 39, 61-74. [CrossRef]

18. Boschma, R.; Eriksson, R.H.; Lindgren, U. Labour market externalities and regional growth in Sweden: The importance of labour mobility between skill-related industries. Reg. Stud. 2014, 48, 1669-1690. [CrossRef]

19. Santoalha, A.; Boschma, R. Diversifying in green technologies in European regions: Does political support matter? Reg. Stud. 2020, 1-14. [CrossRef]

20. Wixe, S.; Andersson, M. Which types of relatedness matter in regional growth? Industry, occupation and education. Reg. Stud. 2017, 51, 523-536. [CrossRef]

21. Rodrik, D. Green industrial policy. Oxf. Rev. Econ. Policy 2014, 30, 469-491. [CrossRef]

22. Shahzad, U.; Ferraz, D.; Doğan, B.; do Nascimento Rebelatto, D.A. Export Product Diversification and $\mathrm{CO}_{2}$ Emissions: Contextual evidences from Developing and Developed Economies. J. Clean. Prod. 2020, 276, 124146. [CrossRef]

23. Romero, J.P.; Gramkow, C. Economic complexity and greenhouse gas emissions. World Dev. 2021, 139, 105317. [CrossRef]

24. UNDP. The 2020 Global Multidimensional Poverty Index (MPI); UNDP: New York, NY, USA, 2020.

25. Nations, U. Framework Convention on Climate Change 2015; United Nations: Paris, France, 2015.

26. Sarwar, S.; Shahzad, U.; Chang, D.; Tang, B. Economic and non-economic sector reforms in carbon mitigation: Empirical evidence from Chinese provinces. Struct. Chang. Econ. Dyn. 2019, 49, 146-154. [CrossRef]

27. Chernow, R. Alexander Hamilton; Penguin Group: New York, NY, USA, 2016.

28. Rosenstein-Rodan, P.N. Problems of industrialisation of eastern and south-eastern Europe. Econ. J. 1943, 53, 202-211. [CrossRef]

29. Rodrik, D. Industrial Policy for the Twenty-First Century; Centre for Economic Policy Research: London, UK, 2004. Available online: https:/ / repec.cepr.org/repec/cpr/ceprdp/DP4767.pdf (accessed on 25 January 2021).

30. Chang, H.-J. The political economy of industrial policy in Korea. Camb. J. Econ. 1993, 17, 131-157. [CrossRef]

31. Hartmann, D.; Zagato, L.; Gala, P.; Pinheiro, F.L. Why Did Some Countries Catch-Up, While Others Got Stuck in the Middle? Stages of Productive Sophistication and Smart Industrial Policies; FGV Sao Paulo School of Economics: Sao Paulo, Brazil, 2020. Available online: https:/ / bibliotecadigital.fgv.br/dspace/bitstream/handle/10438/29123/TD\%20526\%20-\%20PAULO\%20GALA.pdf (accessed on 25 January 2021).

32. Chamberlin, E.H. Theory of Monopolistic Competition: A Re-Orientation of the Theory of Value; Oxford University Press: London, UK, 1949.

33. Acemoglu, D.; Robinson, J.A. Economic Backwardness in Political Perspective; National Bureau of Economic Research: Cambridge, MA, USA, 2002.

34. Bain, D.; Kleinknecht, A. New Concepts in Innovation Output Measurement; Springer: Berlin/Heidelberg, Germany, 2016.

35. Baumol, W.J. The Free-Market Innovation Machine: Analyzing the Growth Miracle of Capitalism; Princeton University Press: Princeton, NJ, USA, 2002.

36. Suzigan, W.; Villela, A.V. Industrial Policy in Brazil; Universidade Estadual de Campinas (UNICAMP), Instituto de Economia: Campinas, Brazil, 1997.

37. Mazzucato, M. From market fixing to market-creating: A new framework for innovation policy. Ind. Innov. 2016, 23, 140-156. [CrossRef] 
38. Hausmann, R.; Hidalgo, C.A. The network structure of economic output. J. Econ. Growth 2011, 16, 309-342. [CrossRef]

39. Ellis, F. Household strategies and rural livelihood diversification. J. Dev. Stud. 1998, 35, 1-38. [CrossRef]

40. Ellis, F. The determinants of rural livelihood diversification in developing countries. J. Agric. Econ. 2000, 51, 289-302. [CrossRef]

41. Benjamin, C. The growing importance of diversification activities for French farm households. J. Rural Stud. 1994, 10, 331-342. [CrossRef]

42. Jebli, M.B.; Youssef, S.B. The environmental Kuznets curve, economic growth, renewable and non-renewable energy, and trade in Tunisia. Renew. Sustain. Energy Rev. 2015, 47, 173-185. [CrossRef]

43. Suri, V.; Chapman, D. Economic growth, trade and energy: Implications for the environmental Kuznets curve. Ecol. Econ. 1998, 25, 195-208. [CrossRef]

44. Geissdoerfer, M.; Savaget, P.; Bocken, N.M.; Hultink, E.J. The Circular Economy-A new sustainability paradigm? J. Clean. Prod. 2017, 143, 757-768. [CrossRef]

45. Kirchherr, J.; Reike, D.; Hekkert, M. Conceptualizing the circular economy: An analysis of 114 definitions. Resour. Conserv. Recycl. 2017, 127, 221-232. [CrossRef]

46. Hartmann, D.; Bezerra, M.; Lodolo, B.; Pinheiro, F.L. International trade, development traps, and the core-periphery structure of income inequality. EconomiA 2020, 21, 255-278. [CrossRef]

47. Van Eck, N.J.; Waltman, L. Software survey: VOSviewer, a computer program for bibliometric mapping. Scientometrics 2010, 84, 523-538. [CrossRef]

48. Jabbour, C.J.C. Environmental training in organisations: From a literature review to a framework for future research. Resour. Conserv. Recycl. 2013, 74, 144-155. [CrossRef]

49. Tranfield, D.; Denyer, D.; Smart, P. Towards a methodology for developing evidence-informed management knowledge by means of systematic review. Br. J. Manag. 2003, 14, 207-222. [CrossRef]

50. Junior, M.L.; Godinho Filho, M. Variations of the kanban system: Literature review and classification. Int. J. Prod. Econ. 2010, 125, 13-21. [CrossRef]

51. Alves, M.W.F.M.; Mariano, E.B. Climate justice and human development: A systematic literature review. J. Clean. Prod. 2018, 202, 360-375. [CrossRef]

52. Mariano, E.B.; Sobreiro, V.A.; Rebelatto, D.A.D. Human development and data envelopment analysis: A structured literature review. Omega-Int. J. Manag. Sci. 2015, 54, 33-49. [CrossRef]

53. Dangelico, R.M. Green product innovation: Where we are and where we are going. Bus. Strategy Environ. 2016, 25, 560-576. [CrossRef]

54. Hartmann, D.; Guevara, M.R.; Jara-Figueroa, C.; Aristarán, M.; Hidalgo, C.A. Linking economic complexity, institutions, and income inequality. World Dev. 2017, 93, 75-93. [CrossRef]

55. Hartmann, D. Economic Complexity and Human Development: How Economic Diversification and Social Networks Affect Human Agency and Welfare; Taylor \& Francis: Abingdon, UK, 2014.

56. Pegels, A.; Lütkenhorst, W. Is Germany's energy transition a case of successful green industrial policy? Contrasting wind and solar PV. Energy Policy 2014, 74, 522-534. [CrossRef]

57. Shadlen, K.C.; Fonseca, E.M.d. Health policy as industrial policy: Brazil in comparative perspective. Politics Soc. 2013, 41, 561-587. [CrossRef]

58. Mathews, J.A. Green growth strategies-Korean initiatives. Futures 2012, 44, 761-769. [CrossRef]

59. Schmidt, T.S.; Schmid, N.; Sewerin, S. Policy goals, partisanship and paradigmatic change in energy policy-analyzing parliamentary discourse in Germany over 30 years. Clim. Policy 2019, 19, 771-786. [CrossRef]

60. Wu, M.; Salzman, J. The Next Generation of Trade and Environment Conflicts: The Rise of Green Industrial Policy. Nw. UL Rev. 2013. Available online: https: / / heinonline.org/HOL/LandingPage?handle=hein.journals/illlr108\&div=17\&id=\&page= (accessed on 25 January 2021).

61. Lanjouw, J.O.; Lanjouw, P. The rural non-farm sector: Issues and evidence from developing countries. Agric. Econ. 2001, 26, 1-23. [CrossRef]

62. Chertow, M.R. “Uncovering” industrial symbiosis. J. Ind. Ecol. 2007, 11, 11-30. [CrossRef]

63. Shanahan, D.F.; Bush, R.; Gaston, K.J.; Lin, B.B.; Dean, J.; Barber, E.; Fuller, R.A. Health benefits from nature experiences depend on dose. Sci. Rep. 2016, 6, 28551. [CrossRef]

64. Wade, R.H. Return of industrial policy? Int. Rev. Appl. Econ. 2012, 26, 223-239. [CrossRef]

65. Barrett, C.B.; Bezuneh, M.; Clay, D.C.; Reardon, T. Heterogeneous Contraints, Incentives, and Income Diversification Strategies in Rural Africa; Department of Applied Economics and Management, Cornell University: New York, NY, USA, 2001. Available online: https:/ /ageconsearch.umn.edu/record/179567/ files/Cornell_Dyson_wp0125.pdf (accessed on 25 January 2021).

66. Blondel, V.D.; Guillaume, J.-L.; Lambiotte, R.; Lefebvre, E. Fast unfolding of communities in large networks. J. Stat. Mech. Theory Exp. 2008, 2008, P10008. [CrossRef]

67. Batagelj, V.; Mrvar, A. Pajek-program for large network analysis. Connections 1998, 21, 47-57.

68. Shannon, P.; Markiel, A.; Ozier, O.; Baliga, N.S.; Wang, J.T.; Ramage, D.; Amin, N.; Schwikowski, B.; Ideker, T. Cytoscape: A software environment for integrated models of biomolecular interaction networks. Genome Res. 2003, 13, 2498-2504. [CrossRef] [PubMed] 
69. Hartmann, D.; Jara-Figueroa, C.; Guevara, M.; Simoes, A.; Hidalgo, C.A. The structural constraints of income inequality in Latin America. arXiv 2017, arXiv:1701.03770.

70. Ferraz, D.; Moralles, H.F.; Campoli, J.S.; de Oliveira, F.C.R.; do Nascimento Rebelatto, D.A. Economic complexity and human development: DEA performance measurement in Asia and Latin America. Gestão Produção 2018, 25, 839-853. [CrossRef]

71. Zhu, S.; Li, R. Economic complexity, human capital and economic growth: Empirical research based on cross-country panel data. Appl. Econ. 2017, 49, 3815-3828. [CrossRef]

72. Lapatinas, A. Economic complexity and human development: A note. Econ. Bull. 2016, 36, 1441-1452.

73. Hamwey, R.; Pacini, H.; Assunção, L. Mapping green product spaces of nations. J. Environ. Dev. 2013, 22, 155-168. [CrossRef]

74. Fraccascia, L.; Giannoccaro, I.; Albino, V. Green product development: What does the country product space imply? J. Clean. Prod. 2018, 170, 1076-1088. [CrossRef]

75. Aldieri, L.; Vinci, C.P. The role of technology spillovers in the process of water pollution abatement for large international firms. Sustainability 2017, 9, 868. [CrossRef]

76. Vandergrift, M.; Kanavos, P. Health policy versus industrial policy in the pharmaceutical sector: The case of Canada. Health Policy 1997, 41, 241-260. [CrossRef]

77. Bailey, D.; Pitelis, C.; Tomlinson, P.R. A place-based developmental regional industrial strategy for sustainable capture of co-created value. Camb. J. Econ. 2018, 42, 1521-1542. [CrossRef]

78. Goga, S.; Bosiu, T.; Bell, J. Linking IDC finance to structural transformation and inclusivity in post-apartheid South Africa. Dev. S. Afr. 2019, 36, 821-838. [CrossRef]

79. Barbieri, N.; Consoli, D. Regional diversification and green employment in US metropolitan areas. Res. Policy 2019, 48, 693-705. [CrossRef]

80. Meckling, J. The developmental state in global regulation: Economic change and climate policy. Eur. J. Int. Relat. 2018, $24,58-81$. [CrossRef]

81. Meckling, J.; Nahm, J. When do states disrupt industries? Electric cars and the politics of innovation. Rev. Int. Political Econ. 2018, 25, 505-529. [CrossRef]

82. Fagerberg, J. Mobilizing innovation for sustainability transitions: A comment on transformative innovation policy. Res. Policy 2018, 47, 1568-1576. [CrossRef]

83. Rogge, K.S.; Dütschke, E. What makes them believe in the low-carbon energy transition? Exploring corporate perceptions of the credibility of climate policy mixes. Environ. Sci. Policy 2018, 87, 74-84. [CrossRef]

84. Sharpley, R. Rural tourism and the challenge of tourism diversification: The case of Cyprus. Tour. Manag. 2002, 23, 233-244 [CrossRef]

85. Shanahan, D.F.; Lin, B.; Gaston, K.; Bush, R.; Fuller, R. What is the role of trees and remnant vegetation in attracting people to urban parks? Landsc. Ecol. 2015, 30, 153-165. [CrossRef]

86. Pugliese, E.; Chiarotti, G.L.; Zaccaria, A.; Pietronero, L. Complex economies have a lateral escape from the poverty trap. PLoS ONE 2017, 12, e0168540. [CrossRef]

87. Binz, C.; Truffer, B.; Coenen, L. Path creation as a process of resource alignment and anchoring: Industry formation for on-site water recycling in Beijing. Econ. Geogr. 2016, 92, 172-200. [CrossRef]

88. Rahut, D.B.; Micevska Scharf, M. Livelihood diversification strategies in the Himalayas. Aust. J. Agric. Resour. Econ. 2012, 56, 558-582. [CrossRef]

89. Mohnen, P.; Röller, L.-H. Complementarities in innovation policy. Eur. Econ. Rev. 2005, 49, 1431-1450. [CrossRef]

90. Wu, R.-J.; Shi, G.-Y.; Zhang, Y.-C.; Mariani, M.S. The mathematics of non-linear metrics for nested networks. Phys. A Stat. Mech. Appl. 2016, 460, 254-269. [CrossRef]

91. Chaudhuri, S.; Mackintosh, M.; Mujinja, P.G. Indian generics producers, access to essential medicines and local production in Africa: An argument with reference to Tanzania. Eur. J. Dev. Res. 2010, 22, 451-468. [CrossRef]

92. Aiginger, K. Industrial policy: A dying breed or a re-emerging phoenix. J. Ind. Compet. Trade 2007, 7, 297-323. [CrossRef]

93. Berhanu, W.; Colman, D.; Fayissa, B. Diversification and livelihood sustainability in a semi-arid environment: A case study from southern Ethiopia. J. Dev. Stud. 2007, 43, 871-889. [CrossRef]

94. Schmitz, H.; Johnson, O.; Altenburg, T. Rent management-The heart of green industrial policy. New Political Econ. 2015, 20, 812-831. [CrossRef]

95. Kemp, R.; Never, B. Green transition, industrial policy, and economic development. Oxf. Rev. Econ. Policy 2017, 33, 66-84. [CrossRef]

96. Van Beers, D.; Bossilkov, A.; Corder, G.; Van Berkel, R. Industrial symbiosis in the Australian minerals industry: The cases of Kwinana and Gladstone. J. Ind. Ecol. 2007, 11, 55-72. [CrossRef]

97. Lapatinas, A.; Garas, A.; Boleti, E.; Kyriakou, A. Economic Complexity and Environmental Performance: Evidence from a World Sample; Munich Personal RePEc Archive: Munich, Germany, 2019. Available online: https://mpra.ub.uni-muenchen.de/92833/1/ MPRA_paper_92833.pdf (accessed on 25 January 2021).

98. Mealy, P.; Teytelboym, A. Economic complexity and the green economy. Res. Policy 2020, 103948. [CrossRef]

99. Huberty, M.; Zachmann, G. Green Exports and the Global Product Space: Prospects for EU Industrial Policy; Bruegel Working Paper; EconStor: Brussels, Belgium, 2011. 
100. Montresor, S.; Quatraro, F. Green technologies and Smart Specialisation Strategies: A European patent-based analysis of the intertwining of technological relatedness and key enabling technologies. Reg. Stud. 2020, 54, 1354-1365. [CrossRef]

101. Perruchas, F.; Consoli, D.; Barbieri, N. Specialisation, diversification and the ladder of green technology development. Res. Policy 2020, 49, 103922. [CrossRef]

102. Fang, Y.; Côté, R.P.; Qin, R. Industrial sustainability in China: Practice and prospects for eco-industrial development. J. Environ. Manag. 2007, 83, 315-328. [CrossRef] [PubMed]

103. Meckling, J.; Sterner, T.; Wagner, G. Policy sequencing toward decarbonization. Nat. Energy 2017, 2, 918-922. [CrossRef]

104. Guevara, M.R.; Hartmann, D.; Aristaran, M.; Mendoza, M.; Hidalgo, C.A. The research space: Using career paths to predict the evolution of the research output of individuals, institutions, and nations. Scientometrics 2016, 109, 1695-1709. [CrossRef]

105. Swain, R.B. A critical analysis of the sustainable development goals. In Handbook of Sustainability Science and Research; Springer: Berlin/Heidelberg, Germany, 2018; pp. 341-355. 